\title{
LA ESTRUCTURA AGRARIA Y LA TENENCIA DE LA TIERRA EN EL SEÑORIO DE ELDA (-)
}

\author{
Glicerio Sánchez Recio \\ Universidad de Alicante
}

El de Elda fue uno más de los señoríos valencianos, repoblado en los primeros años de la segunda década del siglo XVII, después de la expulsión de los moriscos. Su Carta de Población data de 1611-1612, y las cargas económicas que se impusieron a los repobladores, la sitúan a un nivel medio, dentro de las del Vinalopó Medio, entre la más suave del Señorío de Monóvar y la más pesada del de Novelda (1).

\section{1. - FUENTES Y TRATAMIENTO DE LOS DATOS}

Este tema en los señoríos valencianos presenta gandes dificultades para su tratamiento, debidas a la escasez $y$ a las importantes lagunas existentes en las fuentes, al menos en las conocidas y exploradas hasta ahora. Fundamentales para este trabajo son los Cabreves, los Libros de Giradora y los Capatrones de Bienes. Según el profesor Gil Olcina, el Cabreve era «el reconocimiento por el enfiteuta del mencionado domi-

(-) Un avance del presente trabajo fue presentado en las // Jornadas de Metodología $y$ didáctica de la Historia, celebradas en Cáceres del 14 al 16 de diciembre de 1981, titulado: Los Libros de Giradora como fuente para el estudio de la estructura agraria en los Señoríos valencianos. El caso de Elda.

(1) SANCHEZ RECIO, G.: Carta de Población del Señorio de Elda. 1611-1612. Transcripción e Introducción. Elda (Alicante) 1979. BELANDO CARBONELL, R. y SANCHEZ RECIO, G.: Monnover. Una villa de señorío en el siglo XVII. Item. Revista de Ciencias Humanas. $N^{\circ}$ 3. C.E.U. de Alicante; págs. 23-40. Enero-junio 1978. 
nio (directo), con expresión del canon, lindes de la finca, y títulos de pertenencia». Citando a Monforte Báguena, dice que «el cabreve era un uso, no consagrado por la legislación escrita, que contaba con procedimientos y actuaciones judiciales». Finalmente, «el titular del dominio directo podía citar a cabrevar siempre que lo deseara, a expensas suyas; en cambio a costa del enfiteuta, sólo cada diez años». Los Libros de Giradora consisten en la relación de «los enfiteutas por orden alfabético con los sumarios respectivos de bienes censidos, que detallan el valor estimado de establecimiento responción anua $y$, en su caso, superficie de parcelas y cultivos». Estos libros permiten seguir los cambios del dominio útil por las anotaciones marginales o por los nuevos asentamientos, hasta la celebración de un nuevo Cabreve. Este era la base para la confección de los Libros de Giradora (2). Finalmente, los Capatrones de Bienes eran los libros elaborados para el cobro del Equivalente, por lo tanto, más modernos que los anteriores, en los que constaba la relación de todos los propietarios, enfiteutas y terratenientes, la superficie, situación y cultivos de las parcelas, el valor y la renta líquida de las mismas (3).

Para el estudio del Señorío de Elda disponemos de estas Giradoras: La de 1624, utilizada hasta 1627, única en la que aparece el valor y el censo de cada uno de los bienes de los enfiteutas (4). La de 1673, certificación del estado de la Giradora en ese año, presentada por la Señoría en el pleito que habian iniciado los vasallos, cuya principal característica es la distinción que ofrece entre "pechos nuevos" y «pechos viejos», estando, por lo tanto, todas las tierras del Condado sometidas a censo, distinción que no existía en la Giradora de 1624 (5). La de 1716, utilizada hasta 1745-49, primera en la que aparece el cupo de agua que corres-

(2) GIL OLCINA, A.: La propiedad señorial en tierras valencianas. Págs. 50-51. Valencia 1979.

(3) La confección de estos libros debía de ajustarse a las instrucciones dadas desde 1718. A(rchivo) M(unicipal) (de) M(onóvar): Instrucciones para el cobro del Equivalente de 1771. El Profesor E. Giménez López, de la Universidad de Alicante, nos ha proporcionado las Instrucciones dadas en Valencia el 10 de enero y el 20 de febrero de 1782.

(4) A(rchivo) M(unicipal) (de) E(Ida): Giradora de 1624. En la primera página, muy deteriorada, puede leerse: «...Establecidas ...en el año 1612 y agora nuevamente trasladadas de la Jiradora vieja a esta nueva en el presente año de 1624 en el primero de julio de dicho año".

(5) AME: La certificación de la Giradora se halla en el libro «Processo de la Señoría Directa", Folios 21v. - 112. El mencionado pleito terminó mediante una concordia entre el Señor y los vecinos de la villa, según la cual el primero renunciaba al cobro de los «pechos viejos" y los segundos reconocían al Señor otros derechos y privilegios. La Concordia data del 24 de enero de 1684. AME: Varios (Carpeta): Papeles interesantes al pueblo de Elda. $1771-72$. 
ponde a cada una de las parcelas, y en donde se incluyen algunas reclamaciones para que determinados bienes se liberen del pago del censo, en cumplimiento de la anterior Concordia (6). Y la de 1832, aplicada hasta 1839 (7). Aparte de estas, disponemos de la Giradora de Natural de 1771 , en servicio hasta 1840 , en la que constan los propietarios de las tierras no sometidas a censo, indicando la obligación o no del pago del diezmo, y el agua de que disponen (8). Y, finalmente, el Libro Capatrón de los Bienes, de 1777, utilizado hasta 1820, en el que aparecen los enfiteutas, los propietarios y los terratenientes de la Villa, indicando el valor de cada uno de los bienes, casas y tierras, y el agua de que disponen (9).

Una característica común de todos estos libros es que se confeccionaron por orden del Ayuntamiento, a cuyo cargo estaba su custodia y actualización. En los encabezamientos se hace referencia al estado del libro anterior, en la certificación de 1673 se habla de la Giradora Vieja..., y en la de 1716 se indica en la ficha de cada uno de los enfiteutas su «pasa a la Giradora Nueva» (10). Por lo tanto, centrándonos sólo en las

(6) AME: Libro Giradora y Capatrón de la villa de Elda, en donde se hallarán continuadas todas las possesiones de población que poseen diferentes personas en el término de dicha villa con su justo pecho y agua. Se copió el año de 1716. Siendo alcalde...

(7) AME: Giradora de 1832. En la primera página se lee: «En la Sala Capitular de la Villa de Elda a seis de agosto de mil ochocientos treinta y dos: estando juntos y congregados en ella los señores... se propuso: Que era notorio al Ayuntamiento que la expresada Villa tenía y conservaba como hasta aquí lo ha practicado, a cargo del infraescrito Secretario de Cavildo en el Archivo de dicha Sala, entre otros Libros, el Capatrón o Giradora titulada de Población, en donde están notados los bienes, sitios y rahices que respective poseen en este término cada un individuo de la notada Villa, que correspondian al justo pecho al Señorio de la misma, con la dotación de la agua que cada finca tiene para su riego, el cual Libro se hallaba del todo escrito, de manera que no se podía hacer pase alguno en él,... Todo lo cual oido por los demás señores, unánimes y conformes atendiendo a lo justo de la proposición DIXERON: Que desde luego sin pérdida de tiempo se continúe copia de dicho Libro Giradora en el presente a continuación de esta resolución. ...»

(8) AME: Giradora de Natural de la Villa de Elda, mandada copiar por los señores del Ayuntamiento en el año 1771, siendo Escribano... Cuya copia es sacada de la que se formó por Vicente Salazar, Escribano en el año de 1689, en la que están continuadas todas las hacienda naturales de este término..."

(9) AME: Libro Capatrón de Haciendas, en el que se hallarán continuadas, y las casas que posehen los vecinos $y$ terratenientes de la villa de Elda, con sus respectivos precios para el pago y regulación del tanto del Equivalente, que por razón de ellos a cada uno respecte, mandado copiar del antecedente por hallar ya concluido, por el Consejo, Justicia y Regimiento de dicha villa de Elda...».

(10) Esto último se corrobora por los encabezamientos de los distintos libros recogidos en las notas anteriores. Tratando de hallar otras fuentes nos dirigimos por carta, con fcha de 22 de enero de 1980, al actual Conde de Elda, Excmo. Sr. Dn. José Falcó y Alvarez de Toledo, recabándole información sobre los archivos particulares de este Señorío. En su respuesta del 15 de febrero del mismo año, a través del alcalde de Elda, nos decía que dicho archivo habia desaparecido en 1936. 
Giradoras, la duración de cada uno de estos libros, en Elda, fue prolongada, pasando su contenido directamente de uno a otro sin referencia alguna a la confección de Cabreves.

Para el objetivo de nuestro trabajo lo más importante es el contenido de los libros, los datos que aportan las fichas de cada uno de los enfiteutas. Ya hemos dicho antes que junto al nombre de los vasallos se enumeran sus bienes, casas y tierras, y en cuanto a éstas, normalmente, se especifica su extensión en tahullas, el tipo de cultivo, la situación en la partida, con expresión de los linderos, el censo con el que están obligadas al Señor y el agua a partir de 1716. Al margen de cada una de las anotaciones (Items) se expresa el cambio del dominio útil si lo hubiera, con la fórmula: "Pasa a... en fecha de...», indicándolo incluso con una tachadura, $y$ dicho Item se inscribe en la ficha del nuevo poseedor, o se abre una nueva, en el caso de tratarse de un nuevo enfiteuta. Dada la prolongada duración de las Giradoras, cuando un enfiteuta fallece, se utiliza la fórmula: "fenecido» o "finió» y "pasan los bienes a sus herederos».

La abundancia de datos que aportan las Giradoras, comparables a los modernos Amillaramientos, es fundamental para el conocimiento de la economía señorial, cuya veracidad está en función de lo que los censos, la fadiga y el laudemio representaban en las rentas señoriales (11).

En las Giradoras del Señorío de Elda, sin embargo, los anteriores datos aparecen con graves limitaciones. En primer lugar, las Giradoras, a medida que avanzan cronológicamente, van haciendo más complejos sus Items, por las sucesivas transmisiones y repartos hereditarios. Es frecuente hallar la fórmula: "La mitad» o «la tercera parte» etc. "del Item que fue de... y pasó a... etc.». En segundo lugar, son muchos los Items en los que no se da la extensión («...bancales plantados de... en la partida de...), y otros en los que no se indica la partida en la que están situados. En tercer lugar, las transmisiones están apuntadas de forma incompleta, no siempre se dan la fecha de la baja o el nombre del nuevo propietario, y, por lo general, a excepción de la Giradora de 1624, no se datan las nuevas adquisiciones o la aparición de nuevos enfiteutas. De ahí que hayamos utilizado los datos en el momento del cierre de los libros y no se pueda seguir la evolución puntual de la tenencia. Esto último puede completarse con el estudio de los protocolos notariales («Escrituras pecheras») de los años comprendidos entre la apertura y el

(11) GIL OLCINA, A.: O. c.; págs. 36-37 y 44-50. En otro lugar ya nos hemos referido a la veracidad de la documentación y de las listas de reparto elaboradas y controladas por el Ayuntamiento: SANCHEZ RECIO, G.: Elda en 1812. La elección del primer Ayuntamiento Constitucional. Alborada. $N^{\circ} 26$. Elda (Alicante), 1980. 
cierre de cada Giradora (12). La información más completa es, lógicamente, la referente a los censos y al agua a partir de la de 1716 .

Aquí vamos a estudiar las Giradoras de 1716 y de 1832 y tratar, por lo tanto, de la estructura agraria y de la tenencia' de la tierra a mediados del siglo XVIII y en la década de 1830, finales del Antiguo Régimen, y de la evolución de las mismas durante esos ochenta años.

Para el tratamiento del abundante cúmulo de datos que nos ofrecen estas Giradoras, nos ha sido indispensable acudir al procesamiento de los mismos (13). De esta manera hemos podido estudiar los cuatro gandes tipos de cultivos: El olivo, la tierra blanca, la vid y otras (el higueral, el almendrolar, la tierra blanca con olivos, etc.), con sus tres elementos cada uno: extensión, censo y agua, en cada una de las partidas (50 en la Giradora de 1716, y 54 en la de 1832). El tratamiento de los datos nos ha exigido el convertir las cantidades de los censos y el volumen del agua al sistema métrico decimal. Los censos los expresamos en sueldos y dineros (los 12 dineros, equivalentes a un sueldo, los hemos transformado en 10) y el agua en azumbres ( 8 azumbres equivalen a una hora).

\section{2. - LA ESTRUCTURA AGRARIA EN EL SEÑORIO DE ELDA, $1745 / 49-1832 / 39$}

\section{1. - Datos totales y por cultivos}

Más arriba ha quedado dicho que el dato más completo, habida cuenta de la finalidad de la Giradora, es el censo, y, en segundo lugar, el agua; en cambio, los problemas se nos plantean con la extensión de las parcelas cultivadas. De ahí que a través de los dos primeros intentemos aproximarnos al valor del tercero.

\section{Giradora de 1716}

\begin{tabular}{|c|c|c|c|c|c|}
\hline ultivos & Olivo & Tierra $B$. & Vid & Otras & Total \\
\hline & & & & & \\
\hline & 155 & 141 & 294 & 220 & $20 s$ \\
\hline umbres) & 246,5 & 1632,6 & 450,0 & 228,0 & 2512,1 \\
\hline
\end{tabular}

(12) Estos protocolos notariales se hallan en el A(rchivo) (de) $P$ (rotocolos) (de) M(onóvar).

(13) Desde aqui quiero expresar mi agradecimiento a los profesores del Centro de Cálculo de la Universidad de Alicante, Dn. Juan Manuel Pérez y Dn. Angel Esteban, por su indispensable y desinteresada ayuda en la confección de las fichas y en la elaboración del programa. 
Tratando de verificar los anteriores datos, hallamos que la relación existente entre:

Censo total/ Extensión es de.......................................13,4

Censo de la extensión conocida/ Extensión es de .....................6,9

y que el índice de verificación, por lo tanto, es del $51,4 \%$.

\section{Giradora de 1832}

\begin{tabular}{|c|c|c|c|c|c|}
\hline ultivos & Olivo & Tierra $B$. & Vid & Otras & Total \\
\hline & & & & & \\
\hline enso & 119 & 140 & & 253,0 & 225 \\
\hline Igua (azu & 280,0 & 2582,0 & 2294,0 & 37,8 & 51 \\
\hline
\end{tabular}

La relación existente entre:

Censo total/ Extensión es de ..........................................5,1

Censo de la extensión conocida/ Extensión es de ....................4,7 $y$, por lo tanto el índice de verificación es del $92,1 \%$.

A la vista de estos datos son muchos los problemas que se nos plantean. En cuanto a los totales:

a) Es de destacar el distinto nivel del índice de verificación, lo que nos informa acerca de la elaboración más cuidada de la Giradora de 1832. Con el $92,1 \%$ se puede operar con un alto grado de seguridad.

b) Han aumentado considerablemente el volumen del agua disponible, en $106,5 \%$, y la superficie cultivada, en $58,5 \%$ (14).

c) El crecimiento del total de los censos ha sido sólo del $7,9 \%$, y se ha dado, a nivel general, una reducción del censo medio desde el 6,9 al 4,7.

En cuanto a la evolución de las tres variables en cada uno de los cultivos se observa:

a) El gran crecimiento que se da en la vid, que pasa de producir el $14 \%$ de los censos, en la Giradora de 1716 , al $31,2 \%$ en la de 1832 , y que recibía el $16,1 \%$ del agua, en la primera, y el $44,1 \%$, en la segunda. El crecimiento es también muy abultado en la extensión dedicada al cultivo, aunque aquí la verificación, como ya sabemos, es mucho más problemática.

b) En la tierra blanca, en cambio, se observa una pequeña reducción en los censos registrados en una y otra Giradoras, tanto en términos ab- 
solutos, del $1 \%$, como en términos relativos, del $5,6 \%$. Por el contrario, se da un importante crecimiento, en términos absolutos, en cuanto al agua recibida, entre una y otra fechas, del $58 \%$, pero, en términos relativos se pasa del $64,9 \%$ al $49,7 \%$. Respecto a la superficie cultivada, pensamos que no debieron darse importantes variaciones, a la vista de los censos, pero ya es conocida la problemática que existe en esta cuestión.

c) A pesar de esto y del crecimiento dado en la vid, la tierra blanca supuso el principal de los cultivos de Elda, aunque la superficie dedicada a la vid en 1832 era la mayor:

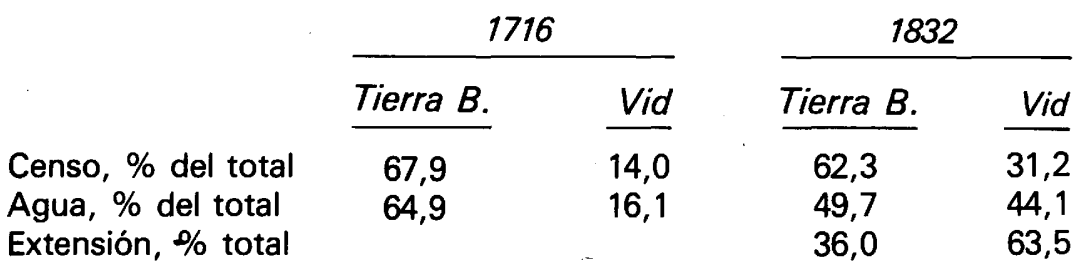

(14) Para aproximarnos al crecimiento de la superficie cultivada hemos operado con la relación existente entre «el censo de la extensión conocida/extensión y el total de los censos»). Según esto resultaría que en la Giradora de 1716 las tahullas cultivadas serían 3029,4 y en la de 1832 serían 4801,7 . De nuevo son los protocolos notariales la fuente principal para verificar el aumento de la extensión cultivada. Como muestra:

APM: FERRANDIS CARRATALA, J. (Escribano Público): Escrituras Públicas de Elda de... Años 1752-61 «...Fue presete el Dr. Dn. Pedro Amat Abogado de los Reales Consejos y de Cámara del Excmo. Sr. Conde de Puñoenrostro, Elda y Ana, mi Sr., y su Procurador Patrimonial, según Escritura..., en él consta entre otras cosas poder establecer sitios para fabricar casas, establecer solares y tierras con las condiciones correspondientes a semejantes contratos,....". (Escrituras de 1754; fol. 4. Ver también los folios $6 \mathrm{v}$. y 11). Se trata en los tres casos de establecimientos de tierras incultas de Elda y de Salinas a vecinos de la villa de Sax.

MONLLOR, A. (Escribano): Escrituras Públicas de Elda de... Año 1763. Fol. 82. Se trata también de un establecimiento de tierras incultas.

En el mapa que acompaña a este trabajo puede verse que la expansión de la superficie cultivada se extiende por las proximidades de las ramblas, de ahí que se intentara aprovechar el agua que esporádicamente correría por ellas. Ver:

MORALES GIL, A.: El riego con aguas de avenida en las laderas subáridas. Papeles del Departamento de Geografia I. Facultad de Filosofía y Letras de la Universidad de Murcia. Curso 1968-69. Pags. 167-183.

En lo que se refiere al aumento del agua disponible:

AME: Cuentas de Clavaría de 1758, fols 8-14: Hay un reparto "...para la limpieza de la azequía del Chopo que se ha mandado executar para lumbrar $y$ aumento de las aguas para el riego de este término en el presente año de 1758...). No se conservan Libros de Clavaría posteriores a ese año. 


\section{CUADRO I \\ GIRADORA DE 1716. RESULTADOS POR PARTIDAS TOTALES}

\begin{tabular}{crrr} 
Partida & Extensión & Censo & Agua \\
\hline 1 & .0 & 3.5 & 8.6 \\
2 & 143.6 & 1825.3 & 21.0 \\
3 & 103.5 & 924.9 & 200.0 \\
4 & 46.5 & 367.8 & 92.0 \\
5 & 55.5 & 414.3 & 68.0 \\
6 & 33.0 & 779.5 & 130.5 \\
7 & 47.5 & 1207.9 & 291.5 \\
8 & 67.4 & 495.6 & 99.5 \\
9 & 27.0 & 373.0 & 39.5 \\
10 & 12.5 & 420.0 & 109.5 \\
11 & .0 & 976.7 & 11.0 \\
12 & 16.0 & 544.0 & 52.5 \\
13 & 26.2 & 326.6 & 49.5 \\
14 & .0 & 2.0 & .0 \\
15 & 51.0 & 616.9 & 67.5 \\
16 & 6.7 & 129.9 & 7.5 \\
17 & 13.5 & 178.1 & 42.5 \\
18 & 489.4 & 2197.8 & 414.5 \\
19 & 67.0 & 327.2 & 21.5 \\
20 & 7.9 & 87.1 & 24.0 \\
21 & .0 & .0 & 2.0 \\
22 & 25.1 & 662.7 & 57.0 \\
23 & 4.0 & 195.0 & 20.0 \\
24 & .0 & 180.1 & 3.0 \\
25 & .0 & 40.0 & .0 \\
26 & 1.0 & 26.3 & 10.5 \\
27 & 4.0 & 2149.1 & 52.5 \\
28 & 1.5 & 29.9 & 10.0 \\
29 & .0 & 12.2 & .5 \\
30 & 4.0 & 30.5 & 15.5 \\
31 & .0 & .0 & 2.0 \\
33 & 2.2 & 44.7 & 3.5 \\
34 & 13.0 & 27.8 & 2.0 \\
35 & 7.2 & 9.8 & .0 \\
36 & .0 & .0 & .0 \\
37 & .0 & .7 & .0 \\
& & &
\end{tabular}




\section{Partida}

38

39

40

41

42

43

44

45

47

48

49

50
Extensión

.0

9.5

.0

24.9

.8

1.5

.0

1.0

3.0

1.5

2.0

242.6
Censo

42.0

100.1

.0

578.0

88.7

58.2

.1

5.7

22.5

36.5

35.8

4427.4 $\frac{\text { Agua }}{12.0}$

12.5

.5

46.5

.0

59.5

.0

1.5

6.0

3.5

12.0

428.5

CUADRO II

GIRADORA DE 1716. PORCENTAJES GLOBALES

Partida

1

2

3

4

5

6

7

8

9

10

11

12

13

14

15

16

17

18

19

20

21

22

23

\section{Extensión}

.0

9.2

6.6

3.0

3.6

2.1

3.0

4.3

1.7

.8

.0

1.0

1.7

.0

3.3

.4

.9

31.3

4.3

.5

.0

1.6

.3
Censo

.0

8.7

4.4

1.8

2.0

3.7

5.8

2.4

1.3

2.0

4.7

2.6

1.6

.0

3.0

.6

.9

10.5

1.6

.4

.0

3.2

.9
Agua

.3

.8

8.0

3.7

2.7

5.2

11.6

4.0

1.6

4.4

.4

2.1

2.0

.0

2.7

.3

1.7

16.5

.9

1.0

.1

2.3

.8 


\begin{tabular}{lrrr} 
Partida & Extensión & Censo & Agua \\
\cline { 2 - 3 } 24 & .0 & .9 & .1 \\
25 & .0 & .2 & .0 \\
26 & .1 & .1 & .4 \\
27 & .3 & 10.3 & .1 \\
28 & .1 & .1 & .4 \\
29 & .0 & .1 & .0 \\
30 & .3 & .1 & .6 \\
31 & .0 & .0 & .1 \\
33 & .1 & .2 & .1 \\
34 & .8 & .1 & .1 \\
35 & .5 & .0 & .0 \\
36 & .0 & .0 & .0 \\
37 & .0 & .0 & .0 \\
38 & .0 & .2 & .5 \\
39 & .6 & .5 & .5 \\
40 & .0 & .0 & .0 \\
41 & 1.6 & 2.8 & 1.9 \\
42 & .1 & .4 & .0 \\
43 & .1 & .3 & 2.4 \\
44 & .0 & .0 & .0 \\
45 & .1 & .0 & .1 \\
47 & .2 & .1 & .2 \\
48 & .1 & .2 & .1 \\
49 & .1 & .2 & .5 \\
50 & 15.5 & 21.2 & 17.1
\end{tabular}

d) El olivo se mantuvo prácticamente estable, según los censos y el agua recibida, con una reducción en los primeros, entre una giradora y ota, del $23,6 \%$, y un aumento en la segunda del $13,5 \%$. La extensión nos plantea el consabido problema. Quizá se diera un aumento de la superficie en el secano, al aplicar la corrección prevista en la Carta de Población (15).

e) Ha desaparecido, prácticamente, el apartado dedicado a otros cultivos (otras), que suponían el $10,5 \%$ de los censos y el $9 \%$ del agua en la Giradora de 1716.

Por todo lo anterior ha de insistirse en el crecimiento experimentado por la vid entre las dos fechas contempladas, que debió beneficiarse del

(15) «...lo dit Señor Conde li plau que los dits pobladores no pagen cens algu en dines de les dites oliveres si tan solament la setsena part de les oliveres que Nostre Señor Deu sera servit donar en cascun any perpetuament...». Carta de Población de Elda, pag. 20. 
aumento de la superficie puesta en cultivo, del aumento del agua disponible y de los cambios de cultivos efectuados. Asimismo pensamos que puede aceptarse un crecimiento de la productividad en los cultivos de la tierra blanca, por el aumento del agua utilizada.

\section{2. - Datos totales por partidas}

La información contenida en la Giradora de 1716, que refleja la situación de 1745-49, acerca de la extensión, los censos y el agua recibida en cada una de las partidas, queda expresada en los cuadros I y II (16). Dejando aparte la extensión, por la problemática que plantea, las partidas más favorecidas por los censos aportados y por el agua recibida son las que aparecen en los cuadros siguientes:

En el Cuadro III, 19 partidas, de las 50 computadas, aportan la casi totalidad de los censos, el $93,6 \%$ del total, y entre ellas destacan la 50 (partida "No especificada»), de ahí el alto grado de incorreción en la elaboración de esta Giradora, la 18 («El Campo»), la 27 («Los Huertos)), y la 2 ("La Almafra»), que suponen el $50,7 \%$ del total de los censos.

(16) De la comparación de uno y otro cuadros, en las partidas: 1, 14, 21, 31, 37, 40 y 44 , los valores 0,0 debian ser levemente positivos, pero no han podido ser reflejados por la máquina. La enumeración de las partidas responde al código que se les ha asignado para su computación. La relación completa de las mismas, según la Giradora de 1716, es:
1. Servera
2. Almafrá
3. Negret
4. Disa
5. Derramador
6. Melich
7. Algualejas
8. Farafis
9. Jaud
10. Asirmat
11. Conde/Jardin
12. Los dos Puentes
13. Albocar
14. Bolón
15. Lumbos
16. San Blas
17. Olmos
18. Campo
19. Campico
20. Carrasca
21. Camino de Petrel
22. Riego de Arriba
23. Riego de Abajo
24. Molino de Arriba
25. Chorrillo
26. El Río
27. Los Huertos
28. La Horteta
29. La Balsa
30. Vergel
31. El Canal
32. El Chopo
33. Las Eras
34. El Fosar
35. Los Sequeros
36. Almazara
37. Jarrería
38. Garrafa
39. Safarjola
40. Musera
41. La Ruaya
42. Portal Mayor
43. El Margen
44. Las Ramblas
45. Casa del Dr. Rico
46. Cabañet
47. Carraxet
48. Contador
49. Los Blancos
50. Sin Especificar 


\section{CUADRO III}

ORDEN DE LAS PARTIDAS SEGUN LOS CENSOS APORTADOS, SUPERIORES AL 1\% (GIRADORA DE 1716)

\begin{tabular}{ccc}
$N^{0}$ Orden & $N^{0}$ de Partida & Censo, $\%$ \\
\cline { 2 - 3 } 1 & 50 & 21,2 \\
2 & 18 & 10,5 \\
3 & 27 & 10,3 \\
4 & 2 & 8,7 \\
5 & 7 & 5,8 \\
6 & 11 & 4,7 \\
7 & 3 & 4,4 \\
8 & 6 & 3,7 \\
9 & 22 & 3,2 \\
10 & 15 & 3,0 \\
11 & 41 & 2,8 \\
12 & 12 & 2,6 \\
13 & 8 & 2,4 \\
14 & 10 & 2,0 \\
15 & 5 & 2,0 \\
16 & 4 & 1,8 \\
17 & 19 & 1,6 \\
18 & 13 & 1,6 \\
19 & 9 & 1,3 \\
& & 13,6
\end{tabular}

De manera semejante al anterior, en el Cuadro $\mathrm{I}$, también 19 partidas reciben el $93 \%$ del total del agua, sobresaliendo la 50 , la 18, la 7 («Algualejas»), y la 3 («El Negret»). No aparecen en este cuadro la 2, que recibe sólo el $0,8 \%$ del agua, la 11 («El Conde/Jardín»), con sólo el $0,4 \%$, y la 19 («El Campico»), con el 0,9\%, aunque ésta en el anterior cuadro aportaba el 1,6\% del censo, y ocupaba el lugar $n^{\circ} 18$. En cambio, están presentes la 43 («El Margen»), que sólo aporta el $0,3 \%$ del censo, la 17 ( (LLos Olmos»), que aporta el 0,9\%, y la 20 («La Carrasca»), con el 0,4 de los censos.

Existe, pues, una importante relación entre el censo aportado y el agua recibida, a pesar de la ausencia de algunas partidas y de la aparición de otras en el cuadro IV respecto al III. 


\section{CUADRO IV}

ORDEN DE LAS PARTIDAS SEGUN EL AGUA QUE RECIBEN,
SUPERIOR AL 1\% DEL TOTAL (GIRADORA DE 1716)

\begin{tabular}{ccc}
$N^{\circ}$ Orden & $N^{0}$ de Partida & Agua $\%$ \\
\cline { 2 - 2 } 1 & 50 & 17,1 \\
2 & 18 & 16,5 \\
3 & 7 & 11,6 \\
4 & 3 & 8,0 \\
5 & 6 & 5,2 \\
6 & 10 & 4,4 \\
7 & 8 & 4,0 \\
8 & 4 & 3,7 \\
9 & 5 & 2,7 \\
10 & 15 & 2,7 \\
11 & 43 & 2,4 \\
12 & 22 & 2,3 \\
13 & 12 & 2,1 \\
14 & 27 & 2,1 \\
15 & 13 & 2,0 \\
16 & 41 & 1,9 \\
17 & 17 & 1,7 \\
18 & 9 & 1,6 \\
19 & 20 & 1,0 \\
& & 93,0
\end{tabular}

Los datos contenidos en la Giradora de 1832, válidos para toda la década de 1830, están recogidos en los cuadros $\vee$ y VI (17). En los cuadros

(17) DE la comparación de los datos de uno y otro cuadros, para las partidas: $24,62,86$ y 90 , en las que alguno de los valores dados en el Cuadro $V /$ es 0,0 , es válido lo dicho en la Nota (16). En la Giradora de 1832 el número total de partidas es 54 . Han desaparecido algunas de la del 1716 y se han incorporado otras nuevas. Las numeradas de la 1 a la 50 mantienen las mismas denominaciones. La relación de las restantes es:

52- Las Cañadas

54- El Castillo

57- S. Antón/Bóveda

58- Los Postigos

59- El Convento

61- El Carril Viejo
62- El Hoyo

71- Casa de Sempere

73- Alfaguara

81- El Barracón

84- El Común

85- Casas de Santo
86- La Sira

87- La Tenería

88- El Colodrill

89- El Vall

90- El Lavador

91- Manguilla 
VII, IX y XI establecemos la jerarquía de las partidas según los censos, el agua, y la extensión de la superficie cultivada en cada una de ellas.

CUADRO V

GIRADORA DE 1832 - RESULTADOS POR PARTIDAS

TOTALES

\begin{tabular}{|c|c|c|c|}
\hline Partida & Extensión & Censo & Agua \\
\hline 1 & 14.2 & 29.1 & 13.0 \\
\hline 2 & 438.2 & 2454.1 & 73.0 \\
\hline 3 & 252.1 & 792.2 & 352.0 \\
\hline 4 & 193.4 & 744.6 & 308.5 \\
\hline 5 & 279.7 & 757.3 & 325.0 \\
\hline 6 & 109.2 & 1334.8 & 326.0 \\
\hline 7 & 481.0 & 1453.1 & 875.0 \\
\hline 8 & 142.4 & 998.1 & 134.0 \\
\hline 9 & 198.2 & 339.1 & 58.0 \\
\hline 10 & 129.1 & 351.4 & 82.5 \\
\hline 11 & 21.8 & 256.1 & 4.5 \\
\hline 12 & 101.6 & 2125.0 & 499.0 \\
\hline 13 & 61.6 & 175.5 & 79.5 \\
\hline 15 & 366.2 & 1189.4 & 94.5 \\
\hline 16 & 74.3 & 675.6 & 119.5 \\
\hline 17 & 110.2 & 141.6 & 223.0 \\
\hline 18 & 737.6 & 1947.8 & 561.5 \\
\hline 19 & 56.1 & 159.1 & 6.0 \\
\hline 20 & 87.6 & 238.4 & 105.0 \\
\hline 22 & 2.7 & 63.2 & 10.5 \\
\hline 23 & 4.2 & 100.1 & 10.0 \\
\hline 24 & 3.5 & .0 & 2.0 \\
\hline 26 & 7.7 & 30.3 & 11.5 \\
\hline 27 & 20.7 & 529.2 & 9.0 \\
\hline 28 & 11.7 & 45.9 & 12.3 \\
\hline 33 & 4.5 & 43.1 & 3.5 \\
\hline 35 & 10.3 & 93.2 & .0 \\
\hline 36 & .0 & 16.3 & .0 \\
\hline 37 & .0 & .0 & .0 \\
\hline 39 & 1.2 & 2.5 & 1.0 \\
\hline 41 & 12.5 & 244.7 & 23.5 \\
\hline 42 & 2.5 & 404.2 & 8.0 \\
\hline
\end{tabular}




\begin{tabular}{c} 
Partida \\
\hline 43 \\
45 \\
47 \\
50 \\
52 \\
54 \\
57 \\
58 \\
59 \\
61 \\
62 \\
71 \\
73 \\
81 \\
84 \\
85 \\
86 \\
87 \\
88 \\
89 \\
90 \\
91
\end{tabular}

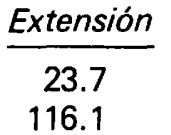

10.0

81.3

10.0

.0

36.1

15.5

21.4

.0

4.0

13.5

35.0

13.0

62.0

4.7

.7

3.7

13.2

3.0

2.0

4.0 $\frac{\text { Censo }}{28.1}$

525.1

49.0

912.6

7.9

.0
301.5

301.5

328.2

30.0

13.3

7.6

87.8

89.3

38.6

1312.2

761.3

5.8

35.5

109.3

54.0

24.0

20.5 $\frac{\text { Agua }}{33.5}$

208.0

12.0

139.5

10.0

.0

51.0

78.5

11.0

.0

5.0

5.5

25.5

65.5

92.5

12.5

5.5

2.5

93.5

.0

5.5

4.0

CUADRO VI

GIRADORA DE 1832 - PORCENTAJES GLOBALES

\begin{tabular}{|c|c|c|c|}
\hline Partida & Extensión & Censo & Agua \\
\hline 1 & .3 & .1 & .3 \\
\hline 2 & 9.9 & 10.9 & 1.4 \\
\hline 3 & 5.7 & 3.5 & 6.8 \\
\hline 4 & 4.4 & 3.3 & 5.9 \\
\hline 5 & 6.3 & 3.4 & 6.3 \\
\hline 6 & 2.5 & 5.9 & 6.3 \\
\hline 7 & 10.9 & 6.4 & 16.8 \\
\hline 8 & 3.2 & 4.4 & 2.6 \\
\hline 9 & 4.5 & 1.5 & 1.1 \\
\hline 10 & 2.9 & 1.6 & 1.6 \\
\hline 11 & .5 & 1.1 & .1 \\
\hline 12 & 2.3 & 9.4 & 9.6 \\
\hline
\end{tabular}


Partida

13

15

16

17

18

19

20

22

24

26

27

28

33

35

36

37

39

41

42

43

45

47

50

52

54

57

58

59

61

62

71

73

81

84

85

86

87

88

89

90

91
Extensión

1.4

8.3

1.7

2.5

16.7

1.3

2.0

.1

.1

.2

.5

.3

.1

.2

.0

.0

.0

.3

.1

.5

2.6

.2

1.8

.2

.0

.8

.4

.5

.0

.1

.3

.8

.3

1.4

.1

.0

.1

.3

.1

.0

.1
Censo

5.3

3.0

.6

8.6

.7

1.1

.3
4

.0

.1

2.3

.2

.2

.1

.0

.0

1.1

1.8

.1

2.3

.2

4.0

.0

1.3

1.5

.1

.1

.0

.4

.4

.2

5.8

3.4

.0

.2

.5

.2

.1

.1 $\frac{\text { Agua }}{1.5}$

1.8

2.3

4.3

10.8

2.1

.2

.2

.0

.2

.2

.1

.0

.0

.0

.0

.5

.2

.6

4.0

.2
2.7

.2

.0

1.0

1.5

.2

.0

.1

.1

.5

1.3

1.8

.2

.1

.0

1.8

.0

.1 
ORDEN DE LAS PARTIDAS SEGUN LOS CENSOS QUE APORTAN SUPERIORES AL 1\% (GIRADORA DE 1832)

\begin{tabular}{|c|c|c|c|}
\hline$N^{\circ}$ Orden & $N^{o}$ de Partida & Censo \% & $\begin{array}{c}\text { \% Censo de } \\
1716 \\
\end{array}$ \\
\hline 1 & 2 & 10,9 & 8,7 \\
\hline 2 & $1 \overline{2}$ & 9,4 & 2,6 \\
\hline 3 & 18 & 8,6 & 10,5 \\
\hline 4 & 7 & 6,4 & 5,8 \\
\hline 5 & 6 & 5,9 & 3,7 \\
\hline 6 & 84 & 5,8 & -- \\
\hline 7 & 15 & 5,3 & 3,2 \\
\hline 8 & 8 & 4,4 & 2,4 \\
\hline 9 & 50 & 4,0 & 21,2 \\
\hline 10 & 3 & 3,5 & 4,4 \\
\hline 11 & 5 & 3,4 & 2,0 \\
\hline 12 & 85 & 3,4 & -- \\
\hline 13 & 4 & 3,3 & 1,8 \\
\hline 14 & 16 & 3,0 & -- \\
\hline 15 & 27 & 2,3 & 10,3 \\
\hline 16 & 45 & 2,3 & -- \\
\hline 17 & 42 & 1,8 & -- \\
\hline 18 & 10 & 1,6 & 2,0 \\
\hline 19 & 9 & 1,5 & 1,3 \\
\hline 20 & 58 & 1,5 & -- \\
\hline 21 & 57 & 1,3 & -- \\
\hline 22 & 20 & 1,1 & -- \\
\hline 23 & 41 & 1,1 & 2,8 \\
\hline \multirow[t]{2}{*}{24} & 11 & 1,1 & 4,7 \\
\hline & Total del censo & $92^{\prime} 2$ & 87,4 \\
\hline
\end{tabular}

En el Cuadro VII, las veinticuatro partidas que, individualmente aportan más del $1 \%$ del total de los censos, suman el $92,9 \%$. Hay que tener en cuenta también la reducción experimentada por la partida 50 , que confirma la mejor elaboración de esta Giradora, y la desaparición de esta lista de las partidas 22 («El Riego de Arriba»), 13 («El Albocar»), y 19. Pero los censos son aportados en diversa proporción por unas y otras: Las diez primeras suman el $64,2 \%$ de los mismos, y sólo las cuatro primeras, el $35,3 \%$, sin embargo, donde los datos son más llamativos es al 
comparar los censos aportados por las partidas en una y otra Giradoras. En conjunto, se ha dado un importante cambio. Las partidas que, en la Giradora de 1716 , habían aportado el $87,4 \%$ de los censos $193,6 \%$ del total menos el $6,4 \%$ de las partidas desaparecidas), en la de 1832, dan sólo el $72,7 \%$ del total. La razón de ello está en las pérdidas tan importantes como la de la partida 50 (del 21,2 al $4,0 \%$ ), la de la 27 (del 10,5 al $2,3 \%$ ), la de la 11 (del 4,7 al $1,1 \%$ ), y la de la 3 (de 10,5 al $8,6 \%$ ), y otras menos importantes, que no pudieron ser compensadas por el crecimiento de otras, como el de la 12 («Los Dos Puentes)) (del 2,6 al 9,4\%), el de la 2 (del 8,7 al 10,9\%), el de la 6 («El Melich») (del 3,7 al 5,9\%), el de la 15 («Lumbos») (del 3,0 al 5,3\%), y el de la 8 ("Farafis») (del 2,4 al $4,4 \%$ ) como más significativos. El $20,2 \%$ restante es aportado por las nuevas partidas, entre las que destacan la 84 («El Común») y la 85 («Las

\section{CUADRO VIII}

VALOR DE LOS CENSOS DE LAS 19 PRIMERAS PARTIDAS, SEGUN EL ORDEN DE 1716, EN AMBAS GIRADORAS, (EN SUELDOS)

\begin{tabular}{|c|c|c|c|}
\hline$N^{\circ}$ Orden & $N^{o}$ de Partida & Censo 1716 & Censo 1832 \\
\hline 1 & 50 & 4427,4 & 912,0 \\
\hline 2 & 18 & 2197,8 & 1947,0 \\
\hline 3 & 27 & 21491 & 529,0 \\
\hline 4 & 2 & 1825,3 & 2454,1 \\
\hline 5 & 7 & 1207,9 & 1453,1 \\
\hline 6 & 11 & 976,7 & 256,1 \\
\hline 7 & 3 & 924,9 & 792,2 \\
\hline 8 & 6 & 779,5 & 1334,8 \\
\hline 9 & 22 & 662,9 & 63,2 \\
\hline 10 & 15 & 616,9 & 1189,4 \\
\hline 11 & 41 & 578,0 & 244,7 \\
\hline 12 & 12 & 544,0 & 2125,0 \\
\hline 13 & 8 & 495,6 & 998,1 \\
\hline 14 & 10 & 420,0 & 351,4 \\
\hline 15 & 5 & 414,3 & 757,3 \\
\hline 16 & 4 & 367,8 & 744,6 \\
\hline 17 & 19 & 327,2 & 159,1 \\
\hline 18 & 13 & 326,6 & 175,5 \\
\hline 19 & 9 & 273,0 & 339,1 \\
\hline & tal de los censos & $\overline{19514,9}$ & $\overline{16825,7}$ \\
\hline
\end{tabular}


Casas de Santo I), y por las que han aumentado su contribución a más del $1 \%$, principalmente la 16 («San Blas»), la 45 («Casa del Dr. Rico») y la 42 («Portal Mayor»).

A través del Cuadro VIII, dada la escasa diferencia que hay en el total de los censos entre una y otra Giradora, se observa un importante paralelismo con el Cuadro VII, y se valora también el peso de la partida 50. Desaparecidas las cantidades de esta partida, los resultados totales de una y otra Giradoras se igualan notablemente; sin embargo, no podemos conocer la redistribución de los censos de dicha partida. Un dato orientativo es que las nuevas partidas que aparecen en la Giradora de 1832 , las comprendidas entre la 52 y la 91 de los cuadros $V$ y VI, aportan 3226,8 sueldos de censo, cantidad muy próxima a los 3515,4 sueldos que hay de diferencia entre los censos de la partida 50 de una y otra Giradoras.

Por lo tanto, los 1665,4 sueldos de diferencia que hay a favor de la $\mathrm{Gi}$ radora de 1832 se deberán a cambios de cultivo o a aumento de la extensión, ya sea en las nuevas partidas, ya en las anteriormente conocidas, ya en àmbos tipos.

En el Cuadro IX aparece el reparto del agua, en tantos por ciento. Del mismo modo que en el Cuadro VII, 23 partidas absorben el $95,2 \%$ del total del agua, aunque se distribuye de forma desigual: las cinco primeras partidas reciben el $50,3 \%$, y las diez primeras, el $73,7 \%$. Dentro de estas últimas destacan las partidas 7,18 y 12, que ocupan también los primeros lugares del Cuadro VII; en cambio, el agua recibida por la partida 2 es ínfima, el 1,4\%.

Es muy importante la comparación de estos datos con los de la Giradora de 1716, de donde se deduce:

a) Las partidas de esta última que aparecen entre las ventitrés primeras de la Giradora de 1832 absorben el $84,3 \%$ del total del agua. Las partidas nuevas, las que no figuraban entre las diecinueve primeras partidas de 1716 absorben el 15,1\%, entre las que cabe destacar la 45, con el $4 \%$; en cambio, tiene aquí menos importancia la 84 , con sólo el $1,8 \%$ del total. De lo que se deduce una pérdida relativa del $4,2 \%$ del agua en las partidas que en 1832 continuaban con más del $1 \%$ del total del agua.

b) Hay pérdidas relativas importantes en las partidas:

18 del $5,7 \%$

3 del $1,2 \%$

10 «Asirmat» del $2,8 \%$

8 Del 1,4\% 


\section{CUADRO IX}

ORDEN DE LAS PARTIDAS SEGUN EL AGUA QUE RECIBEN, SUPERIOR AL 1\% DEL TOTAL (GIRADORA DE 1832)

\begin{tabular}{|c|c|c|c|}
\hline$N^{\circ}$ Orden & $N^{o}$ de partida & Agua, \% & $\%$, Agua de 1716 \\
\hline 1 & 7 & 16,8 & 11,6 \\
\hline 2 & 18 & 10,8 & 16,5 \\
\hline 3 & 12 & 9,6 & 2,1 \\
\hline 4 & 3 & 6,8 & 8,0 \\
\hline 5 & 5 & 6,3 & 2,7 \\
\hline 6 & 6 & 6,3 & 5,2 \\
\hline 7 & 4 & 5,9 & 3,7 \\
\hline 8 & 17 & 4,3 & 1,7 \\
\hline 9 & 45 & 4,0 & \\
\hline 10 & 50 & 2,7 & 17,1 \\
\hline 11 & 8 & 2,6 & 4,0 \\
\hline 12 & 16 & 2,3 & \\
\hline 13 & 20 & 2,0 & 1,0 \\
\hline 14 & 15 & 1,8 & 2,7 \\
\hline 15 & 84 & 1,8 & \\
\hline 16 & 88 & 1,8 & \\
\hline 17 & 10 & 1,6 & 4,4 \\
\hline 18 & 13 & 1,5 & 2,0 \\
\hline 19 & 58 & 1,5 & \\
\hline 20 & 2 & 1,4 & \\
\hline 21 & 81 & 1,3 & \\
\hline 22 & 9 & 1,1 & 1,6 \\
\hline 23 & 57 & 1,0 & \\
\hline \multicolumn{2}{|c|}{ Total del agua } & $\overline{95,2}$ & $\overline{84,3}$ \\
\hline
\end{tabular}

$y$ hay aumentos relativos notables en las partidas:

12 del $7,5 \%$

$$
7
$$
del $5,2 \%$

5 «Derramador» del $3,6 \%$ 17 del $2,6 \%$

4 «Disa» del $2,2 \%$

En el Cuadro $X$, en cuanto a las cantidades absolutas del agua recibida, aparece una situación bien distinta a la del Cuadro VIII, dado el crecimiento del agua utilizada, superior al 100 por 100 , durante la época 
VOLUMEN DEL AGUA RECIBIDA EN LAS 19 PRIMERAS PARTIDAS, SEGUN EL ORDEN DE 1716, EN AMBAS GIRADORAS, EN AZUMBRES.

\begin{tabular}{|c|c|c|c|}
\hline$N^{\circ}$ Orden & $N^{o}$ de Partida & Agua de 1716 & Agua de 1832 \\
\hline 1 & 50 & 428,5 & 139,5 \\
\hline 2 & 18 & 414,5 & 561,5 \\
\hline 3 & 7 & 291,5 & 875,0 \\
\hline 4 & 3 & 200,0 & 352,0 \\
\hline 5 & 6 & 130,5 & 326,0 \\
\hline 6 & 10 & 109,5 & 82,0 \\
\hline 7 & 8 & 99,5 & 82,5 \\
\hline 8 & 4 & 92,0 & 308,5 \\
\hline 9 & 5 & 68,0 & 325,0 \\
\hline 10 & 15 & 67,5 & 94,5 \\
\hline 11 & 43 & 59,5 & 33,5 \\
\hline 12 & 22 & 57,0 & 10,5 \\
\hline 13 & 12 & 52,5 & 449,0 \\
\hline 14 & 27 & 52,5 & 9,0 \\
\hline 15 & 13 & 49,5 & 79,5 \\
\hline 16 & 41 & 46,5 & 23,5 \\
\hline 17 & 17 & 42,5 & 223,0 \\
\hline 18 & 9 & 39,5 & 58,0 \\
\hline \multirow[t]{2}{*}{19} & 20 & 24,0 & 105,0 \\
\hline & Total del agua & 2325,0 & $\overline{4187,5}$ \\
\hline
\end{tabular}

abarcada. De ahí que sólo reciban menos agua en 1832 las partidas: 50, por las razones ya dichas, las que han desaparecido entre las veintitrés primeras $(43,22,27,41)$, y la 10 y la 8 , aunque éstas, en cantidades mínimas, a pesar de su importante descenso relativo. La partida 18 , a pesar de su caída relativa, recibe en términos absolutos el $35,4 \%$ más de agua. El aumento global de estas diez y nueve partidas, sin embargo, es inferior al aumento global de todas las partidas de una Giradora a otra, el $80 \%$ respecto al $106,7 \%$.

Por otra parte, el agua recibida por las partidas nuevas, de la 52 a la 91, asciende sólo a 467'5 azumbres (Cuadro VI), lo que supone sólo el 9\% del total del agua, y el $17^{\prime} 4 \%$ del aumento del agua en la Giradora de 1832 respecto a la de 1716 . De ahí que el $82,6 \%$ de dicho aumento, 2681,7 azumbres fueran recibidos en las antiguas partidas. 


\section{CUADRO XI}

ORDEN DE LAS PARTIDAS SEGUN LA EXTENSION CULTIVADA,
SUPERIOR AL 1\% DEL TOTAL (GIRADORA DE 1832)

\begin{tabular}{r}
$N^{\circ} \mathrm{O}$ \\
\hline 1 \\
2 \\
3 \\
4 \\
5 \\
6 \\
7 \\
8 \\
9 \\
10 \\
11 \\
12 \\
13 \\
14 \\
15 \\
16 \\
17 \\
18 \\
19 \\
20
\end{tabular}

\begin{tabular}{c}
$N^{0}$ de Partida \\
\hline 18 \\
7 \\
2 \\
15 \\
5 \\
3 \\
9 \\
4 \\
8 \\
10 \\
45 \\
17 \\
6 \\
12 \\
20 \\
50 \\
16 \\
13 \\
84 \\
19
\end{tabular}

Extensión, \%

1

2

3

4

5

6

7

8

9

10

11

12

13

14

15

16

17

18

19

19

16,7

10,9

9,9

8,3

6,3

5,7

4,5

4,4

3,2

2,9

2,6

2,5

2,5

2,3

2,0

1,8

1,7

1,4

1,4

1,3

Total de la Extensión

$\overline{92,3 \%}$

En el Cuadro XI, se ordenan las partidas, según la extensión cultivada. De modo semejante a lo visto en los cuadros VII y IX, veinte partidas abarcan el $92,3 \%$ del total de la superficie, cinco de ellas más del $50 \%$, y las diez primeras, el $72,8 \%$. Destacan, por su alto porcentaje, la 18 , la 7 , la 2 , y la 15. De las partidas "nuevas», sólo aparece en esta serie la 84.

Volviendo a los valores absolutos, de las 4413,6 tahullas de esta Giradora, sólo 228,8 pertenecen a las partidas nuevas, el 5,1\%. De ahí que de las 1772,3 tahullas de crecimiento teórico de la superficie cultivada, entre una y otra Giradoras, las partidas nuevas supondrían, al máximo, 248,4 (el 14\%). Según lo cual, la mayor parte de dicho crecimiento se habría dado en las partidas que ya aparecen en las Giradoras de 1716 (18).

(18) Ver lo dicho en la (14). 
De todo lo dicho anteriormente, puede verse que la extensión, el censo y el agua de las partidas nuevas, su relación con el total y con el crecimiento habido entre ambas Giradoras son como siguen:

\begin{tabular}{|c|c|c|c|}
\hline & Total & $\%$ del total & $\%$ Cecmto. total \\
\hline xte & 248,4 & 5,18 & 14,0 \\
\hline enso & 3515,8 & 15,57 & 111,0 \\
\hline Agua & 467,5 & 9,0 & 17,4 \\
\hline
\end{tabular}

Estos datos nos plantean un serio problema, porque, si bien puede existir un paralelismo entre las cifras correspondientes a la extensión y al

CUADRO XII

ORDEN DE LAS PARTIDAS CON MAS DEL 1\% DEL TOTAL DEL CENSO, DEL AGUA, Y DE LA EXTENSION. (GIRADORA DE 1832)

\begin{tabular}{|c|c|c|c|}
\hline$N^{o}$ Orden & $\begin{array}{c}N^{o} \text { Partd. } / \\
\text { Censo }\end{array}$ & $\begin{array}{c}\text { No Partd. } / \\
\text { Agua }\end{array}$ & $\begin{array}{c}N^{o} \text { Partd. } \\
\text { Extens. }\end{array}$ \\
\hline 1 & 2 & 7 & 18 \\
\hline 2 & 12 & 18 & 7 \\
\hline 3 & 18 & 12 & 2 \\
\hline 4 & 7 & 3 & 15 \\
\hline 5 & 6 & 5 & 5 \\
\hline 6 & 84 & 6 & 3 \\
\hline 7 & 15 & 4 & 9 \\
\hline 8 & 8 & 17 & 4 \\
\hline 9 & 50 & 45 & 8 \\
\hline 10 & 3 & 50 & 10 \\
\hline 11 & 5 & 8 & 45 \\
\hline 12 & 85 & 16 & 17 \\
\hline 13 & 4 & 20 & 6 \\
\hline 14 & 16 & 15 & 12 \\
\hline 15 & 27 & 84 & 20 \\
\hline 16 & 45 & 88 & 50 \\
\hline 17 & 42 & 10 & 16 \\
\hline 18 & 10 & 13 & 13 \\
\hline 19 & 9 & 58 & 84 \\
\hline 20 & 58 & 2 & 19 \\
\hline 21 & 57 & 81 & -- \\
\hline 22 & 20 & 9 & -- \\
\hline 23 & 41 & 57 & -- \\
\hline 24 & 11 & -- & -- \\
\hline
\end{tabular}


agua, este se rompe con las del censo. Lo que nos haría concluir que estas nuevas partidas, de extensión reducida, pero recibiendo agua en volumen ligeramente superior a la media total, soportarian censos más altos, a la vez que se habría dado una reducción de los mismos en las anteriores partidas. El problema más árduo estriba en las limitaciones que encontramos respecto a la extensión de la superficie cultiva, da al no poder establecer con seguridad el crecimiento habido entre ambas Giradoras, ni, incluso, la de 1832, por la imprecisión de las medidas.

Finalmente, en el Cuadro XII, hemos recogido las partidas en el orden que aparecen en los cuadros $\mathrm{VII}, \mathrm{IX}$, y XI, buscando entre ellas una posible relación, de manera que la posición que una ocupa en cada serie pueda explicarse en función de las otras dos: De este modo, y a manera de ejemplo, la partida 2 ("Almafra»), que ocupa el primer lugar en cuanto al censo, $v$ el tercero por la extensión, ocupa el número veinte por el agua; de ahí deduciriamos la relación principal censo-extensión. La partida 12 ("Los dos Puentes») ofrece una relación importante entre el censo-agua (segundo y tercer lugar respectivamente), en cambio, por la extensión ocupa el lugar número catorce. Etc.

\section{3. - LA LOCALIZACION DE LAS PARTIDAS}

En el mapa adjunto (19) aparece la localización de las partidas, aunque con exactitud sólo hemos logrado situar veintinueve de estas. La mayor parte se hallan en el valle, junto al río, donde las disponibilidades de agua eran mayores, y en las proximidades de la población, y siete, de la 52 a la 90 , pertenecen al grupo de las que sólo aparecen en la Giradora de 1832, y éstas, a excepción de la 73 y de la 90 , están en la periferia, en altitudes próximas o superiores a los 400 metros y en las cercanías de las ramblas. En las últimas es en las que se dieron las roturaciones que ampliaron la superficie cultivada en la segunda mitad del siglo XVIII.

Entre las partidas localizadas en el mapa se hallan las de mayor peso en ambas Giradoras, como puede verse en los cuadros anteriores, aunque hay ausencias notables, como las de:
41- La Ruaya
8- Farafis
13- Albocar

17- Olmos

58- Los postigos

(19) Agradecemos al Profesor Gregorio Canales, del Departamento de Geografia de la Universidad de Alicante, la colaboración en la confección del mapa, y a los funcionarios municipales de Elda Srs. Poveda Ortuño y Juan Romero su ayuda para la localización de las partidas. 
Otras, en cambio, debían estar en las proximidades y dentro de los límites del recinto de la población, ya que algunas, incluso, llevan los nombres de las calles:

16- S. Blas

21- Camino de Petrel

22- Riego de Arriba

23- Riego de Abajo

27- Los Huertos
33- Las Eras

34- El Fosar

35- Los Sequeros

36- La Almazara

37. Jarrería
42- Portal Mayor (calle)

54- Castillo (calle)

59- Convento (calle)

61- Carril Viejo

89- El Vall (calle)

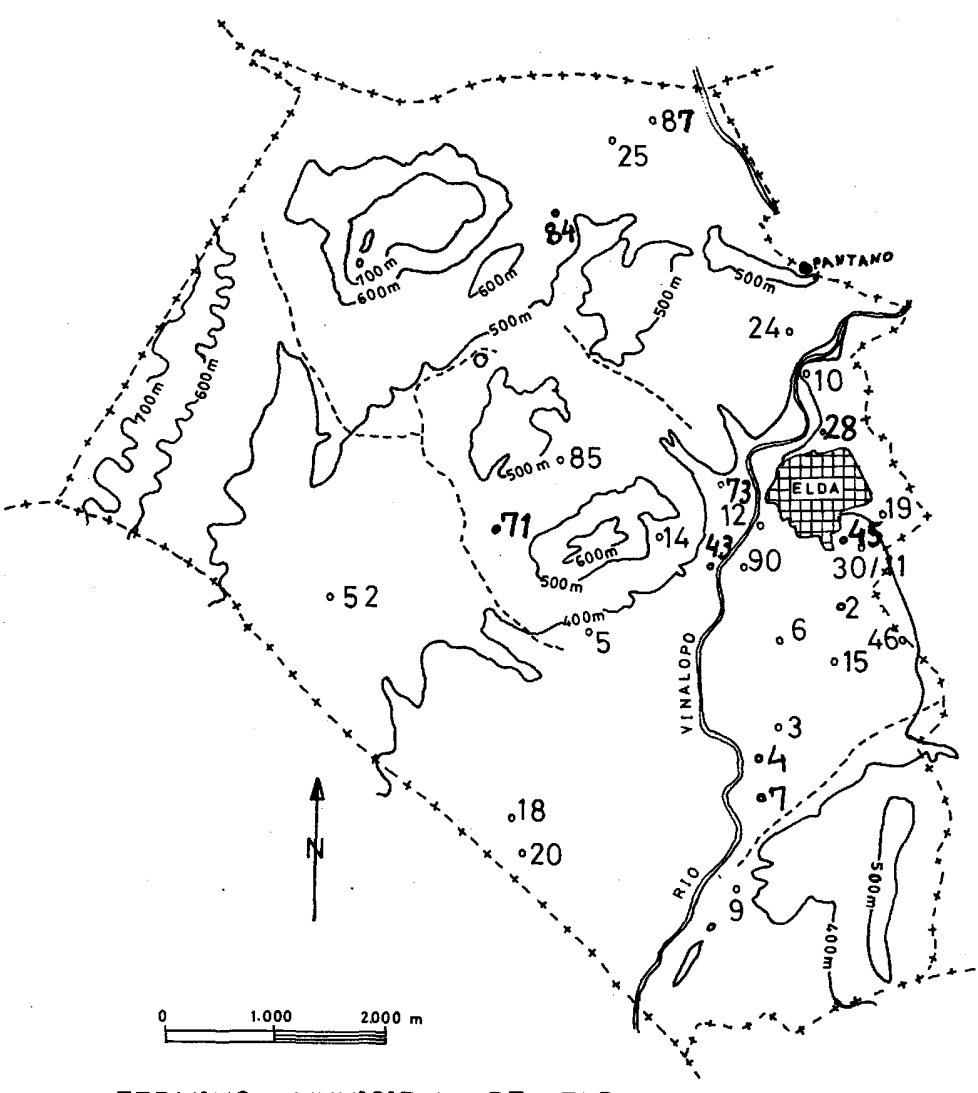

TERMINO MUNICIPAL DE ELDA 


\section{PARTIDAS QUE APARECEN EN EL MAPA}

2- Almafrá

3- Negret

4- Disa

5- Derramador

6- Melich

7- Algualejas

9- Jaud

10- Asirmat

11- Conde/Jardín

12- Los dos Puentes
14- Bolón

15- Lumbos

18- El Campo

19- El Campico

20- Carrasca

24- Molino de Arriba

25- Chorrillo

28- Horteta

30- Vergel

43- El Margen
45- Casa del Dr. Rico

46- Huerta Nueva

52- Las Cañadas

71- Casa de Sempere

73- Alfaguara

84- El Común

85- Casas de Santo

87- Tenería

90- Lavador

\section{4. - LA ḌISTRIBUCION DE LOS CULTIVOS EN LAS PARTIDAS}

\subsection{1- LA GIRADORA DE 1716}

En el Cuadro XIII aparecen estructurados los datos de esta Giradora. Aquí trataremos únicamente de las cifras del censo y del agua en cada tipo de cultivo, dada la problemática que existe con la extensión.

\section{a) LA TIERRA BLANCA}

Los cultivos predominantes son los que se realizan en tierra blanca, sin plantaciones, sean cereales o algunos hortícolas. En esta Giradora la tierra blanca aporta los censos y recibe el agua siguiente:

\begin{tabular}{|c|c|c|c|}
\hline & Total & $\%$ del total & Censo/Agua \% \\
\hline Cens & $\begin{array}{l}\text { 14199,9 suel. } \\
1632,6 \text { azumb. }\end{array}$ & $\begin{array}{l}67,9 \\
64,9\end{array}$ & 1,04 \\
\hline
\end{tabular}

De ahi la importancia que, a mediados del siglo XVIII, tenía la tierra blanca en Elda.

En el Cuadro XIII, en primer lugar, se ve que la tierra blanca está presente en la casi totalidad de las partidas, a excepción de siete, que son, a la vez, partidas con extensiones mínimas de superficie cultivada (20), $y$, en segundo lugar, la escasez de tierras que carecen totalmente de agua.

(20) Esas partidas son la 21, 28, 31, 36, 40, 42 y 45 . Se da incluso la particularidad de la partida 1 , que recibe agua y no paga censo, pudiéndose tratar de un pequeño alodio que aún no ha sido transferido a la Giradora de Natural. 
RESULTADOS PARCIALES POR PARTIDAS Y CULTIVOS (GIRADORA DE 1716)

\begin{tabular}{|c|c|c|c|c|c|c|c|c|c|c|c|c|}
\hline \multirow[b]{2}{*}{ Partida } & \multicolumn{3}{|c|}{ Olivo } & \multicolumn{3}{|c|}{ Tierra Blanca } & \multicolumn{3}{|c|}{ Viña } & \multicolumn{3}{|c|}{ Otras } \\
\hline & Exten. & Censo & Agua & Exten. & Censo & Agua & Exten. & Censo & Agua & Exten. & Censo & Agua \\
\hline 1 & 0 & .0 & .0 & .0 & .0 & 8.1 & 0 & 3.5 & .5 & .0 & .0 & .0 \\
\hline 2 & .0 & .0 & .0 & 51.5 & 845.1 & 21.0 & 79.4 & $\pi 3.5$ & .0 & 12.7 & 206.7 & .0 \\
\hline 3 & .0 & .0 & 30.0 & 42.5 & 340.7 & 58.0 & 60.0 & 571.0 & 105.5 & 1.0 & 13.2 & .6 .5 \\
\hline 4 & .0 & 20.0 & 9.5 & 8.5 & 71.6 & 18.5 & 36.5 & 269.2 & 62.5 & 1.5 & 7.0 & 1.5 \\
\hline 5 & .0 & .0 & .0 & 38.5 & 329.3 & 59.5 & 17.0 & 77.8 & 8.5 & .0 & 7.2 & .0 \\
\hline 6 & .0 & .0 & .0 & 30.5 & 690.4 & 102.0 & 2.5 & 89.1 & 28.5 & .0 & .0 & .0 \\
\hline 7 & .0 & 38.7 & 10.0 & 41.5 & 1022.5 & 248.0 & 3.0 & 64.1 & 13.5 & 3.0 & 82.6 & 20.0 \\
\hline 8 & .0 & .0 & 17.0 & 63.9 & 471.6 & 77.5 & 3.5 & 24.0 & 5.0 & .0 & .0 & .0 \\
\hline 9 & .0 & .0 & .0 & 27.0 & 56.9 & 21.0 & .0 & .0 & .0 & .0 & 216.1 & 18.5 \\
\hline 10 & .0 & .0 & 4.0 & 12.5 & 291.1 & 88.5 & .0 & .0 & .0 & .0 & 128.9 & 17.0 \\
\hline & 0 & 945.3 & 6.5 & .0 & 20.2 & 1.5 & .0 & .0 & .0 & .0 & 11.2 & 3.0 \\
\hline $\begin{array}{l}11 \\
12\end{array}$ & .0 & $\begin{array}{l}946.3 \\
.0\end{array}$ & $\begin{array}{r}6.5 \\
.0\end{array}$ & 16.0 & $\begin{array}{r}204.2 \\
464.0\end{array}$ & $\begin{array}{l}1.5 \\
44.5\end{array}$ & .0 & .0 & 0 & .0 & 80.0 & 8.0 \\
\hline 13 & 7.0 & 39.0 & 5.0 & 9.7 . & 135.4 & 24.0 & 7.5 & 46.0 & 11.5 & 2.0 & 106.2 & 9.0 \\
\hline 14 & .0 & .0 & .0 & .0 & 2.0 & .0 & .0 & .0 & .0 & .0 & .0 & .0 \\
\hline 15 & .0 & .0 & 1.0 & 24.5 & 174.2 & 32.0 & 17.0 & 165.8 & 16.5 & 9.5 & 276.9 & 18.0 \\
\hline 16 & 3.0 & 53.3 & 3.5 & 3.7 & 58.8 & 4.0 & .0 & .0 & .0 & .0 & 17.8 & .0 \\
\hline 17 & .0 & .0 & .0 & 1.0 & 106.8 & 27.0 & 4.5 & 65.3 & 10.5 & 8.0 & 6.0 & 5.0 \\
\hline 18 & 3.5 & 250.7 & 41.0 & 138.2 & 954.9 & 181.0 & 275.2 & 650.2 & 122.0 & 72.5 & 342.0 & 70.5 \\
\hline 19 & 21.2 & 53.7 & 21.0 & 22.7 & 173.5 & .5 & 12.2 & 70.9 & .0 & 10.9 & 29.1 & .0 \\
\hline 20 & .0 & .0 & .0 & 7.9 & 87.1 & 24.0 & .0 & .0 & 0 & .0 & .0 & .0 \\
\hline 21 & 0 & .0 & 2.0 & .0 & .0 & .0 & .0 & .0 & .0 & .0 & .0 & .0 \\
\hline 22 & 0 & .0 & .0 & 25.1 & 662.7 & 57.0 & .0 & .0 & .0 & .0 & .0 & .0 \\
\hline 23 & 0 & .0 & .0 & 4.0 & 195.0 & 20.0 & .0 & 0 & .0 & .0 & .0 & .0 \\
\hline 24 & .0 & .0 & .0 & .0 & .1 & .0 & .0 & .0 & .0 & .0 & 180.0 & 3.0 \\
\hline 25 & .0 & .0 & .0 & .0 & 40.0 & .0 & .0 & .0 & .0 & .0 & .0 & .0 \\
\hline 26 & .0 & .0 & .0 & 1.0 & 26.3 & 10.5 & .0 & .0 & .0 & .0 & & .0 \\
\hline 27 & .0 & .0 & .0 & 4.0 & 2021.5 & 46.0 & .0 & .0 & .0 & .0 & 127.6 & 6.5 \\
\hline 28 & 1.5 & 29.9 & 10.0 & .0 & & .0 & .0 & .0 & .0 & .0 & .0 & .0 \\
\hline 29 & .0 & .0 & & .0 & 12.2 & .5 & .0 & .0 & .0 & .0 & .0 & .0 \\
\hline $\begin{array}{l}29 \\
30\end{array}$ & 4.0 & 14.3 & 11.0 & .0 & $\begin{array}{l}16.2 \\
16.2\end{array}$ & 4.5 & .0 & .0 & .0 & .0 & .0 & .0 \\
\hline 31 & .0 & .0 & 2.0 & .0 & 0 & .0 & .0 & .0 & .0 & .0 & .0 & .0 \\
\hline 33 & .0 & .0 & .0 & 2.2 & 44.7 & 3.5 & .0 & .0 & .0 & .0 & .0 & .0 \\
\hline 34 & 0 & .0 & .0 & 13.0 & 13.6 & 1.0 & .0 & .0 & .0 & 0 & 14.2 & 1.0 \\
\hline 35 & .0 & .0 & .0 & 7.2 & 9.8 & .0 & .0 & 0 & .0 & .0 & .0 & .0 \\
\hline 36 & 0 & 0 & 0 & .0 & .0 & .0 & .0 & .0 & .0 & .0 & .0 & .0 \\
\hline $\begin{array}{l}36 \\
37\end{array}$ & .0 & .0 & .0 & .0 & .7 & .0 & .0 & .0 & .0 & .0 & .0 & .0 \\
\hline 38 & .0 & .0 & .0 & .0 & 42.0 & 12.0 & .0 & .0 & .0 & .0 & .0 & .0 \\
\hline 39 & .0 & .0 & .5 & 5.0 & 71.2 & 6.0 & 1.5 & 16.7 & 3.0 & 3.0 & 12.2 & 3.0 \\
\hline 40 & .0 & .0 & .5 & .0 & & .0 & .0 & .0 & .0 & .0 & .0 & .0 \\
\hline 41 & .0 & .0 & .0 & 24.9 & 578.0 & 46.5 & .0 & .0 & .0 & .0 & .0 & .0 \\
\hline $\begin{array}{l}41 \\
42\end{array}$ & .0 & .0 & .0 & .0 & .0 & .0 & .0 & .0 & .0 & .8 & 88.7 & .0 \\
\hline 43 & 1.5 & .0 & 39.0 & 0 & 58.2 & 20.5 & .0 & .0 & .0 & .0 & .0 & .0 \\
\hline 44 & .0 & .0 & . & .0 & .1 & .0 & .0 & .0 & .0 & .0 & & .0 \\
\hline 45 & .0 & .0 & .0 & .0 & .0 & 0 & 1.0 & 5.7 & 1.5 & .0 & .0 & .0 \\
\hline 47 & 0 & 0 & 0 & 3.0 & 22.5 & 6.0 & .0 & .0 & .0 & 0 & .0 & .0 \\
\hline 48 & .0 & .0 & .0 & 1.5 & 36.5 & 3.5 & .0 & .0 & U & 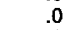 & .0 & 0 \\
\hline 49 & .0 & .0 & .0 & .0 & 25.1 & 2.5 & 2.0 & 10.7 & 9.5 & .0 & .0 & \\
\hline 50 & 14.4 & 112.1 & 33.0 & 189.5 & 4026.4 & 351.5 & 9.0 & 41.2 & 6.5 & 29.7 & 247.7 & 37.5 \\
\hline
\end{tabular}

En el Cuadro XIV establecemos la jerarquía de las partidas principales en función del porcentaje de los censos respecto del total del tipo de cultivo, con el agua que reciben y la relación del censo y el agua. Nos encontramios que las venticuatro partidas que aparecen en el cuadro suponen el $96,9 \%$ de los censos y el $95,4 \%$ del agua. Las dos primeras 
aportan el $42,5 \%$ de los censos y el $24,3 \%$ del agua; pero como la primera es la partida 50, si prescindimos de ella, las partidas, desde la segunda a la décima, aportan el $53,9 \%$ de los censos y el $49,9 \%$ del agua. Vemos el peso de las partidas, aparte la 50 , de la 27, la 7, la 18, y la 2, que ocupan los primeros lugares. En la última columna, hemos establecido la relación entre el censo y el agua, en tantos por ciento, según la cual las partidas peor abastecidas, las de los valores más altos, son la 2 ,

\section{CUADRO XIV}

ORDEN DE LAS PARTIDAS, QUE APORTAN MAS DE 50

SUELDOS, SEGUN EL \% DEL TOTAL DE LOS CENSOS DE LA TIERRA BLANCA, CON EL \% DEL AGUA Y LA RELACION DEL CENSO/AGUA (GIRADORA DE 1716)

\begin{tabular}{|c|c|c|c|c|}
\hline$N^{o}$ Orden & $N^{\circ}$ de Partida & $\%$ Censo & $\%$ Agua & $\begin{array}{c}\text { Censo/ } \\
\text { Agua }\end{array}$ \\
\hline 1 & 50 & 28,3 & 21,5 & 1,3 \\
\hline 2 & 27 & 14,2 & 2,8 & 5,0 \\
\hline 3 & 7 & 7,2 & 15,1 & 0,4 \\
\hline 4 & 18 & 6,7 & 11,0 & 0,6 \\
\hline 5 & 2 & 5,9 & 1,2 & 4,9 \\
\hline 6 & 6 & 4,8 & 6,2 & 0,7 \\
\hline 7 & 22 & 4,6 & 3,4 & 1,3 \\
\hline 8 & 41 & 4,0 & 2,8 & 1,4 \\
\hline 9 & 8 & 3,3 & 4,7 & 0,7 \\
\hline 10 & 12 & 3,2 & 2,7 & 1,1 \\
\hline 11 & 3 & 2,3 & 3,5 & 0,6 \\
\hline 12 & 5 & 2,3 & 3,6 & 0,6 \\
\hline 13 & 10 & 2,0 & 5,4 & 0,3 \\
\hline 14 & 23 & 1,3 & 1,2 & 1,0 \\
\hline 15 & 15 & 1,2 & 1,9 & 0,6 \\
\hline 16 & 19 & 1,2 & -- & -- \\
\hline 17 & 13 & 0,9 & 1,4 & 0,6 \\
\hline 18 & 17 & 0,7 & 1,6 & 0,4 \\
\hline 19 & 20 & 0,6 & 1,4 & 0,4 \\
\hline 20 & 4 & 0,5 & 1,1 & 0,4 \\
\hline 21 & 39 & 0,5 & 0,3 & 1,6 \\
\hline 22 & 16 & 0,4 & 0,2 & 2,0 \\
\hline 23 & 43 & 0,4 & 1,2 & 0,3 \\
\hline \multirow[t]{2}{*}{24} & 9 & 0,4 & 1,2 & 0,3 \\
\hline & Totales: & 96,9 & $\overline{95,4}$ & \\
\hline
\end{tabular}


la 5 («El Derramador»), la 22 («El Riego de Arriba»), la 21 («Camino de Petre|»), etc., y las de aportes más importantes, con valores más bajos, son la 43 («El Margen»), y la 8 ("La Jaud»), que ocupan los últimos lugares por razón del censo, la 13 y la 3.

\section{CUADRO XV}

ORDEN DE LAS PARTIDAS, CON MAS DE 50 SUELDOS, SEGUN EL \% DEL TOTAL DE LOS CENSOS DE LA VID, CON EL \% DEL AGUA Y LA RELACION DEL CENSO/AGUA (GIRADORA DE 1716)

\begin{tabular}{|c|c|c|c|c|}
\hline$N^{\circ}$ Orden & $N^{o}$ de Partida & $\%$ Censo & $\%$ Agua & $\begin{array}{c}\text { Censo } \\
\text { Agua }\end{array}$ \\
\hline 1 & 2 & 26,2 & -- & -- \\
\hline 2 & 18 & 22,0 & 30,1 & 0,7 \\
\hline 3 & 3 & 19,3 & 26,0 & 0,7 \\
\hline 4 & 4 & 9,1 & 15,4 & 0,5 \\
\hline 5 & 15 & 5,6 & 4,0 & 1,4 \\
\hline 6 & 6 & 3,0 & 7,0 & 0,4 \\
\hline 7 & 5 & 2,6 & 2,0 & 1,3 \\
\hline 8 & 19 & 2,4 & -- & -- \\
\hline 9 & 17 & 2,2 & 2,5 & 0,8 \\
\hline \multirow[t]{2}{*}{10} & 7 & 2,1 & 3,3 & 0,6 \\
\hline & Totales: & 95,5 & 98,3 & \\
\hline
\end{tabular}

b) LA VID

Este cultivo supone en censos y agua:

\begin{tabular}{|c|c|c|c|}
\hline & Total & $\%$ del total & Censo/Agua \% \\
\hline Censo & 2944,7 & 14,0 & 0,8 \\
\hline gu & 405,0 & 16,1 & \\
\hline
\end{tabular}

De donde se deduce la importancia relativa del cultivo y el buen abastecimiento de agua.

En el Cuadro XIII aparece la concentración del cultivo en muy pocas partidas, de las que en sólo diez los censos son superiores a los cincuenta sueldos, que son las que aparecen en el Cuadro $X V$, y que aportan el $95,5 \%$ de los censos y absorben el $98,3 \%$ del agua. Las cuatro primeras suponen el $76,7 \%$ de los censos y el $71,5 \%$ del agua. La relación por- 
centual entre los censos y el agua es relativamente buena, a excepción de las partidas 2, que ocupa el primer puesto por los censos, y de la 19, en el octavo lugar.

c) EL OLIVO

En primer lugar, el olivo, por censos y agua, representa:

\begin{tabular}{|c|c|c|c|}
\hline & Total & $\%$ del total & Censo/Agua \% \\
\hline $\begin{array}{c}\text { Censo } \\
\text { Aqua }\end{array}$ & $\begin{array}{l}1557,0 \\
246,5\end{array}$ & $\begin{array}{l}7,4 \\
98\end{array}$ & 0,7 \\
\hline
\end{tabular}

La importancia, por lo tanto, de este cultivo es bastante inferior a la de la vid; en cambio, es mejor la relación censo/agua, aunque aquí hay que tener en cuenta otro elemento, la reducción del censo del olivo a costa de la elevación del diezmo (21). De ahí que, como puede apreciarse en el Cuadro XIII, en algunas partidas aparezca agua y no se dé censo. Como ocurría con la vid, también el olivo se concentra en unas partidas, pero en las que los censos superan los cincuenta sueldos son solamente cinco, como aparece en el Cuadro XVI. Estas suponen el $90,7 \%$ de los censos, pero sólo el $42,4 \%$ del agua. En cuanto a los censos destacan dos partidas, la 11 , con el $60,7 \%$ de los censos, y la 18 , con el $16,1 \%$ de los mismos. La relación censo/agua de estas partidas es muy diverso, sobresale el mal abastecimiento de la partida 11 y el deficiente de la 18.

\section{d) OTRAS}

Ya conocemos el significado de este término. Se trata de los cultivos no incluidos en los anteriores: almendro, higueras, mezclas de estos con otros o de los anteriores entre sí. En esta Giradora, en total, representan:

\begin{tabular}{cccc} 
& Total & $\%$ del total & Censo/Agua \% \\
\cline { 2 - 2 } Censo & 2201,3 & $\begin{array}{c}10,5 \\
\text { Agua }\end{array}$ & 9,0
\end{tabular}

Lo cual supone una importancia relativa. Este tipo de cultivos aparece disperso, como se ve en el Cuadro XIII, aproximadamente en la mitad de la partidas, pero, sobre todo, en las de mayor amplitud e intensidad de cultivo.

(21) Ver la Nota (15). 
CUADRO XVI

ORDEN DE LAS PARTIDAS CON MAS DE 50 SUELDOS, SEGUN EL \% DEL TOTAL DE LOS CENSOS DEL OLIVO, CON EL \% DEL AGUA Y LA RELACION DEL CENSO/AGUA (GIRADORA DE 1716)

\begin{tabular}{|c|c|c|c|c|}
\hline$N^{\circ}$ Orden & $N^{\circ}$ de Partida & $\%$ Censo & $\%$ Agua & $\begin{array}{c}\text { Censo } \\
\text { Agua }\end{array}$ \\
\hline 1 & 11 & 60,7 & 2,6 & 23,3 \\
\hline 2 & 18 & 16,1 & 16,6 & 1,0 \\
\hline 3 & 50 & 7,1 & 13,3 & 0,5 \\
\hline 4 & 19 & 3,4 & 8,5 & 0,4 \\
\hline \multirow[t]{2}{*}{5} & 16 & 3,4 & 1,4 & 2,4 \\
\hline & Totales: & $\overline{90,7}$ & $\overline{42,4}$ & \\
\hline
\end{tabular}

CUADRO XVII

ORDEN DE LAS PARTIDAS CON MAS DE 50 SUELDOS, SEGUN EL \% DEL TOTAL DELOS CENSOS DE OTRAS, CON EL \% DEL AGUA Y LA RELACION DEL CENSO/AGUA (GIRADORA DE 1716)

\begin{tabular}{|c|c|c|c|c|}
\hline$N^{\circ}$ Orden & $N^{o}$ de Partida & $\%$ Censo & $\%$ Agua & $\begin{array}{c}\text { Censo } \\
\text { Agua }\end{array}$ \\
\hline 1 & 18 & 15,5 & 30,9 & 0,5 \\
\hline 2 & 15 & 12,5 & 7,8 & 1,6 \\
\hline 3 & 50 & 11,2 & 16,4 & 0,6 \\
\hline 4 & 9 & 9,8 & 8,1 & 1,2 \\
\hline 5 & 2 & 9,3 & -- & -- \\
\hline 6 & 24 & 8,1 & 1,3 & 6,2 \\
\hline 7 & 10 & 5,8 & 7,4 & 0,7 \\
\hline 8 & 27 & 5,7 & 2,8 & 2,0 \\
\hline 9 & 13 & 4,8 & 3,9 & 1,2 \\
\hline 10 & 42 & 4,0 & -- & -- \\
\hline 11 & 7 & 3,7 & 8,7 & 0,4 \\
\hline \multirow[t]{2}{*}{12} & 12 & 3,6 & 3,5 & 1,0 \\
\hline & Totales: & 94,0 & 90,8 & \\
\hline
\end{tabular}


En el Cuadro XVII hemos recogido las doce que aportan más de cincuenta sueldos de censo, y que en conjunto suponen el $94,0 \%$ de los mismos y el $90,8 \%$ del agua. Sobresalen las partidas: $18,15,9$ y 2 , que suponen el $47,1 \%$ del total de los censos y el $46,8 \%$ del agua, habida cuenta de la falta de la misma en la partida 2. En cambio, la partida 50 sólo cuenta con el $11,2 \%$ de los censos y con el $16,4 \%$ del agua. Los valores de la relación censo/agua se aproximan o superan, en su mayoría, a la unidad, $y$, por tanto, el abastecimiento es deficiente.

\section{CUADRO XVIII \\ ORDENACION DE LAS PARTIDAS, SEGUN LOS CENSOS DE CADA UNO DE LOS CULTIVOS (GIRADORA DE 1716)}

Part./

\begin{tabular}{|c|c|c|c|c|}
\hline$N^{0}$ Orden & Tierra $B$ & Part. / Vid & Part. / Olivo & Part. /Otras \\
\hline 1 & 50 & 2 & 11 & 18 \\
\hline 2 & 27 & 18 & 18 & 15 \\
\hline 3 & 7 & 3 & 50 & 50 \\
\hline 4 & 18 & 4 & 19 & 9 \\
\hline 5 & 2 & 15 & 16 & 2 \\
\hline 6 & 6 & 6 & -- & 24 \\
\hline 7 & 22 & 5 & -- & 10 \\
\hline 8 & 41 & 19 & -- & 27 \\
\hline 9 & 8 & 17 & -- & 13 \\
\hline 10 & 12 & 7 & $-\ldots$ & 42 \\
\hline 11 & 3 & -- & -- & 7 \\
\hline 12 & 5 & -- & -- & 12 \\
\hline 13 & 10 & -- & -- & -- \\
\hline 14 & 23 & -- & -- & -- \\
\hline 15 & 15 & & & \\
\hline 16 & 19 & & & \\
\hline 17 & 13 & & & \\
\hline 18 & 17 & & & \\
\hline 19 & 20 & & & \\
\hline 20 & 4 & & & \\
\hline 21 & 39 & & & \\
\hline 22 & 16 & & & \\
\hline 23 & 43 & & & \\
\hline 24 & 9 & & & \\
\hline
\end{tabular}


Finalmente, a través del Cuadro XVIII, pretendemos ver las partidas en las que predominan los censos de un determinado cultivo. Como casos más destacados aparecen:

\begin{tabular}{|c|c|c|c|c|c|c|c|}
\hline \multicolumn{2}{|c|}{ Tierra Blanca } & \multicolumn{2}{|c|}{ Vid } & \multicolumn{2}{|c|}{ Olivo } & \multicolumn{2}{|c|}{ Otras } \\
\hline$N^{\circ}$ Part. & \% Part. & $N^{\circ}$ Part. & $\%$ Part. & $N^{\circ}$ Part. & $\%$ Part. & $N^{o}$ Part. & $\%$ Part. \\
\hline 22 & 100,0 & 4 & 73,00 & 11 & 96,7 & 9 & 79,1 \\
\hline 41 & 100,0 & -- & -- & 16 & 41,0 & 24 & 100,0 \\
\hline 8 & 95,0 & & & -- & -- & 42 & 100,0 \\
\hline
\end{tabular}

En las restantes partidas se simultanean unos y otros cultivos en mayor proporción.

\subsection{2. - LA GIRADORA DE 1832}

En el Cuadro $X I X$ se hallan recogidos todos los datos sobre la extensión, el censo y el agua de cada uno de los tipos de cultivos en cada una de las partidas. A partir de él hemos elaborado otros, con los que se comprenderán mejor dichos datos.

\section{a) LA TIERRA BLANCA}

A la altura de 1830 también predominaban los cultivos sobre tierra blanca, extendidos prácticamente por todas las partidas. Las cifras eran:

\begin{tabular}{lrrccc} 
& Total & \% del tot. & & $\begin{array}{c}\text { Censo/ } \\
\text { Agua \% }\end{array}$ & $\begin{array}{c}\text { Censo/ } \\
\text { Ext. \% }\end{array}$ \\
\cline { 2 - 2 } Censo & 14065,5 & 62,3 & & 1,2 & \\
Agua & 2582,0 & 49,7 & & \\
Extensión & 1593,1 & 36,0 & &
\end{tabular}

Aunque estas son cantidades importantes, si las comparamos con las de mediados del siglo XVIII, Giradora de 1716, encontramos una leve reducción, en cuanto al censo, del $0,9 \%$ en términos absolutos, y del $5,4 \%$ en términos relativos, y un importnte crecimiento en cuanto al agua, del $36,8 \%$ en términos absolutos, pero, en términos relativos se ha registrado un descenso del $15,2 \%$. Lo cual significa una gran alteración en la distribución del agua por cultivos. Por consiguiente, la relación censo/agua también ha cambiado, en perjuicio de la segunda, siempre en términos relativos. 


\section{CUADRO XIX}

RESULTADOS PARCIALES POR PARTIDAS Y CULTIVOS

(GIRADORA DE 1832)

\begin{tabular}{|c|c|c|c|c|c|c|c|c|c|c|c|c|}
\hline \multirow[b]{2}{*}{ Partida } & \multicolumn{3}{|c|}{ Olivo } & \multicolumn{3}{|c|}{ Tierra blanca } & \multicolumn{3}{|c|}{ Viña } & \multicolumn{3}{|c|}{ Otras } \\
\hline & Exten. & Censo & Agua & Exten. & Censo & $\underline{\text { Agua }}$ & Exten. & Censo & Agua & Exten & Censo & Agua \\
\hline 1 & .0 & .0 & .0 & .7 & 3.5 & .5 & 13.5 & 25.6 & 12.5 & .0 & .0 & 10 \\
\hline 2 & 131.4 & 521.2 & 30.0 & 122.9 & 604.2 & 16.0 & 164.7 & 1254.9 & 27.0 & 19.2 & 73.8 & .0 \\
\hline 3 & 5.5 & 16.0 & 5.0 & 22.9 & 137.9 & 22.5 & 223.7 & 638.3 & 324.5 & .0 & .0 & .0 \\
\hline 4 & 1.0 & 9.0 & 2.0 & 22.2 & 107.6 & 84.0 & 170.2 & 628.0 & 222.5 & .0 & .0 & .0 \\
\hline 5 & 24.0 & 100.1 & 31.5 & 93.9 & $2 \pi .0$ & 95.5 & 161.8 & 380.2 & 198.0 & .0 & .0 & 0 \\
\hline 6 & .0 & .0 & .0 & 106.2 & 1319.3 & 291.5 & 3.0 & 15.5 & 34.5 & .0 & .0 & .0 \\
\hline 7 & 21.1 & 58.9 & 87.0 & 193.1 & 923.5 & 413.5 & 266.8 & 470.7 & 372.5 & .0 & .0 & 2.0 \\
\hline 8 & 2.5 & 15.1 & 2.0 & 130.7 & 956.4 & 125.5 & 9.2 & 26.6 & 6.5 & .0 & .0 & .0 \\
\hline 9 & .0 & .0 & 2.0 & 20.0 & 43.8 & 16.0 & 134.7 & 256.3 & 31.0 & 43.5 & 39.0 & 9.0 \\
\hline 10 & 24.0 & 47.4 & 11.5 & 83.1 & 215.2 & 64.5 & 16.0 & 71.8 & .0 & 6.0 & 17.0 & 6.5 \\
\hline 11 & .0 & .0 & .0 & 16.3 & 256.1 & .0 & 5.5 & .0 & 4.5 & .0 & .0 & .0 \\
\hline 12 & .0 & .0 & .0 & 101.6 & 2125.0 & 499.0 & .0 & .0 & .0 & .0 & .0 & .0 \\
\hline 13 & 15.2 & 53.9 & 13.5 & 26.4 & 84.7 & 64.0 & 20.0 & 36.9 & 2.0 & .0 & .0 & .0 \\
\hline 15 & 5.0 & 10.1 & .0 & 7.2 & 13.2 & 2.0 & 348.0 & 1139.6 & 86.5 & 6.0 & 26.5 & 6.0 \\
\hline 16 & 3.0 & 4.9 & 5.0 & 68.8 & 670.7 & 111.0 & .0 & & .0 & 2.5 & .0 & 3 \\
\hline 17 & 5.0 & 8.1 & 12.5 & 65.0 & 30.8 & 44.5 & 40.2 & 102.7 & 166.0 & .0 & .0 & 0 \\
\hline 18 & 23.5 & 30.8 & 15.0 & 187.3 & 580.1 & 138.0 & 514.8 & 1281.0 & 400.0 & 12.0 & 56.1 & 8.5 \\
\hline 19 & 39.1 & 74.8 & .0 & 14.0 & 67.1 & 4.5 & 2.0 & 8.0 & 1.5 & 1.0 & 9.2 & .0 \\
\hline 20 & 7.0 & 21.2 & 7.0 & .0 & .0 & .0 & 80.6 & 217.2 & 98.0 & .0 & .0 & 0 \\
\hline 22 & .0 & .0 & .0 & 2.7 & 63.2 & 10.5 & .0 & .0 & .0 & .0 & .0 & . \\
\hline 23 & .0 & .0 & .0 & 4.2 & 100.1 & 10.0 & .0 & .0 & .0 & .0 & .0 & .0 \\
\hline 24 & .0 & .0 & .0 & 3.5 & .0 & 2.0 & .0 & .0 & .0 & .0 & .0 & 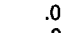 \\
\hline 26 & .0 & 10.4 & 4.0 & 7.7 & 19.9 & 7.5 & .0 & .0 & .0 & .0 & .0 & .0 \\
\hline 27 & .0 & .0 & .0 & 20.7 & 529 & 9.0 & .0 & .0 & .0 & .0 & .0 & \\
\hline 28 & 5.5 & 22.6 & 6.0 & 4.2 & 23 & 4.0 & .0 & .0 & .0 & 2.0 & .0 & 2. \\
\hline 33 & .0 & .0 & .0 & 4.5 & 43 & 3.5 & .0 & .0 & .0 & .0 & .0 & \\
\hline 35 & 3.2 & 5.9 & .0 & 7.1 & 87.3 & .0 & .0 & .0 & .0 & .0 & .0 & .0 \\
\hline 3 & .0 & .0 & .0 & .0 & 16.3 & .0 & .0 & .0 & .0 & .0 & .0 & .0 \\
\hline 3 & .0 & .0 & .0 & .0 & .0 & .0 & .0 & .0 & .0 & .0 & .0 & .0 \\
\hline 3 & 1.2 & 2.5 & 1.0 & .0 & .0 & .0 & .0 & .0 & .0 & .0 & .0 & .0 \\
\hline 41 & .0 & .0 & .0 & 12.5 & 244.7 & 23.5 & .0 & .0 & .0 & .0 & .0 & .0 \\
\hline 4 & .0 & .0 & .0 & 2.5 & 40 & 8.0 & .0 & .0 & .0 & .0 & .0 & .0 \\
\hline 4 & 18.7 & 16.4 & 27.5 & 5.0 & 1 & 6.0 & .0 & .0 & .0 & .0 & .0 & .0 \\
\hline 45 & 9.4 & 34.5 & 7.0 & 23.0 & 237 & 57.5 & 83.7 & 253.5 & 143.5 & .0 & .0 & .0 \\
\hline 47 & .0 & .0 & .0 & 9.0 & 49.0 & 11.0 & 1.0 & .0 & 1.0 & .0 & .0 & \\
\hline 50 & 7.5 & 106.3 & 1.5 & 40.3 & 705 & 98.5 & 31.5 & 99.8 & 39.5 & 2.0 & 1.4 & \\
\hline 5 & 4.5 & 2.1 & 8.0 & 5.5 & 5.8 & 2.0 & .0 & .0 & .0 & .0 & .0 & 0 \\
\hline 5 & .0 & .0 & .0 & .0 & & .0 & .0 & .0 & .0 & .0 & .0 & 0 \\
\hline 5 & .0 & 1.4 & .0 & 36.1 & 300.1 & 51.0 & .0 & .0 & .0 & .0 & .0 & $n$ \\
\hline 5 & .0 & .0 & .0 & 11.5 & 320.7 & 48.5 & 4.0 & 7.5 & 30.0 & .0 & .0 & \\
\hline 5 & 1.7 & .0 & 1.0 & 3.2 & & 2.5 & 14.5 & .0 & 7.5 & 2.0 & 30.0 & .0 \\
\hline 6 & .0 & .0 & .0 & .0 & 13 & .0 & .0 & .0 & .0 & .0 & .0 & 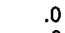 \\
\hline 6 & .0 & .0 & .0 & 4.0 & & 5.0 & .0 & .0 & .0 & .0 & .0 & \\
\hline 7 & 2.0 & 10.2 & .0 & 5.0 & 17 & 4.0 & 6.5 & 60.2 & 1.5 & .0 & .0 & \\
\hline 7 & .0 & .0 & .0 & 5.0 & 48.5 & 5.0 & 30.0 & 40.8 & 20.5 & .0 & .0 & \\
\hline 0 & .0 & .0 & .0 & 1.0 & 5.0 & 10.0 & 12.0 & 33.6 & 55.5 & .0 & .0 & \\
\hline 8 & .0 & .0 & .0 & 62.0 & 131 & 9 & .0 & .0 & .0 & .0 & .0 & \\
\hline 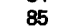 & .0 & .0 & .0 & 4.7 & 761.3 & 12.5 & .0 & .0 & .0 & .0 & .0 & 0 \\
\hline 8 & .0 & .0 & .0 & .0 & .0 & .0 & .7 & 5.8 & 5.5 & .0 & .0 & \\
\hline 8 & .0 & .0 & .0 & 3.7 & 35.5 & 2.5 & .0 & .0 & .0 & .0 & .0 & a \\
\hline 8 & .0 & .0 & .0 & 13.2 & 109.3 & 93.5 & .0 & .0 & .0 & .0 & .0 & 0 \\
\hline 8 & .0 & .0 & .0 & 3.0 & 54 & 0 & .0 & .0 & .0 & .0 & .0 & \\
\hline 9 & .0 & .0 & .0 & 2.0 & 24.0 & 5.5 & .0 & .0 & .0 & .0 & .0 & \\
\hline & & & & 4.0 & 20.5 & 4.0 & .0 & .0 & .0 & .0 & .0 & \\
\hline
\end{tabular}


A través del Cuadro $X I X$ vemos que los cultivos de tierra blanca se hallan repartidos, prácticamente, por todas las partidas; pero es el Cuadro $X X$ el que nos da mayor claridad sobre esta cuestión. En él puede verse, en primer lugar, que las veintiocho partidas que aportan más de cincuenta sueldos de censo cada una suponen el $96,8 \%$ del total de los censos, el 93,5\% del agua, y el 93,0\% de la extensión; pero hay una gran desigualdad entre ellas, porque las seis primeras partidas suponen el $52,2 \%$ de los censos, el $52,2 \%$ del agua, y el $41,9 \%$ de la extensión. En segundo lugar, si comparamos este cuadro con el XIV veremos cómo se ha alterado el orden de las partidas, e, incluso, algunas han desaparecido. Las que se repiten en ambos cuadros aportan, en el

\section{CUADRO XX}

ORDEN DE LAS PARTIDAS CON MAS DE 50 SUELDOS, SEGUN EL \% DEL TOTAL DE LOS CENSOS DE LA TIERRA BLANCA, CON EL \% DEL AGUA Y DE LA EXTENSION, Y LA RELACION CENSO/AGUA Y CENSO/EXTENSION (GIRADORA DE 1832)

\begin{tabular}{|c|c|c|c|c|c|c|}
\hline$N^{\circ}$ Ord. & $N^{o}$ Partida & $\%$ Censo & \% Agua & $\%$ Extens. & Cens/Agua & Cens/Ext. \\
\hline 1 & 12 & 15,0 & 19,3 & 6,3 & 0,7 & 2,3 \\
\hline 2 & 6 & 9,3 & 11,2 & 6,6 & 0,8 & 1,4 \\
\hline 3 & 84 & 9,3 & 3,5 & 3,8 & 2,6 & 2,4 \\
\hline 4 & 8 & 6,7 & 4,8 & 8,2 & 1,3 & 0,8 \\
\hline 5 & 7 & 6,5 & 16,0 & 12,1 & 0,4 & 0,5 \\
\hline 6 & 85 & 5,4 & 0,4 & 2,9 & 13,5 & 1,8 \\
\hline 7 & 50 & 5,0 & 3,8 & 2,5 & 1,3 & 2,0 \\
\hline 8 & 16 & 4,7 & 4,2 & 4,3 & 1,1 & 1,0 \\
\hline 9 & 2 & 4,2 & 0,8 & 7,7 & 5,2 & 0,5 \\
\hline 10 & 18 & 4,1 & 5,3 & 11,7 & 0,8 & 0,3 \\
\hline 11 & 27 & 3,7 & 0,3 & 1,2 & 12,0 & 3,0 \\
\hline 12 & 42 & 2,8 & 0,3 & 0,1 & 9,3 & 28,0 \\
\hline 13 & 58 & 2,2 & 1,8 & 0,7 & 1,2 & 3,1 \\
\hline 14 & 57 & 2,1 & 1,9 & 2,2 & 1,1 & 0,9 \\
\hline 15 & 5 & 1,9 & 3,6 & 5,8 & 0,5 & 0,3 \\
\hline 16 & 11 & 1,8 & -- & 1,0 & -- & 1,8 \\
\hline 17 & 41 & 1,7 & 0,9 & 0,7 & 1,8 & 2,4 \\
\hline 18 & 45 & 1,6 & 2,2 & 1,4 & 0,7 & 1,1 \\
\hline 19 & 10 & 1,5 & 2,4 & 5,2 & 0,6 & 0,2 \\
\hline 20 & 3 & 0,9 & 0,8 & 1,3 & 1,1 & 0,6 \\
\hline 21 & 88 & 0,7 & 3,6 & 0,8 & 0,1 & 0,8 \\
\hline 22 & 4 & 0,7 & 3,2 & 1,3 & 0,2 & 0,5 \\
\hline 23 & 23 & 0,7 & 0,3 & 0,2 & 3,5 & 3,5 \\
\hline 24 & 35 & 0,6 & -- & 0,4 & -- & 1,5 \\
\hline 25 & 13 & 0,6 & 2,4 & 1,6 & 0,2 & 0,3 \\
\hline 26 & 19 & 0,4 & 0,1 & 0,8 & $\therefore \quad 4,0$ & 4,0 \\
\hline 27 & 22 & 0,4 & 0,4 & 0,1 & 1,0 & 4,0 \\
\hline 28 & 89 & 0,3 & -- & 0,1 & -- & 0,3 \\
\hline Totales \% & & 96,8 & 93,5 & $\overline{93,0}$ & & \\
\hline
\end{tabular}


XX sólo el $66,6 \%$ y en el XIV el $93,1 \%$ de los censos. $Y$, en tercer lugar, vemos que entre las seis primeras partidas se hallan dos de las que hemos denominado «nuevas», la 84 y la 85 . Finalmente, en las dos últimas columnas del Cuadro XX, hemos establecido, en tantos por ciento, las relaciones censo/agua y censo/extensión, tratando de hallar, en términos relativos, el nivel de abastecimiento del agua y la razón del censo. En esta última cuestión es difícil llegar a unas conclusiones claras, porque si en unos casos la relación es inversa, es decir que a mayor volumen de agua corresponde menor extensión, $o$ al contrario, $y$, por lo tanto, la razón principal del censo sería respectivamente el agua o la extensión, como ocurre en las partidas 12, 9,2,8, etc.; en otros casos se da casi un paralelismo, es decir que pesaría tanto uno como otro elemento en la razón del censo, como sucede en las partidas $84,7,57$, 4, etc.; en otros, finalmente, la relación no es tan clara, porque, aún siendo inversa la proporción, se trata de partidas mal abastecidas de agua, como en la $85,27,58,41$, etc.

\section{CUADRO XXI}

\footnotetext{
ORDENACION DE LAS PARTIDAS, DE AMBAS GIRADORAS, CON MAS DE 50 SUELDOS, SEGUN EL TOTAL DE LOS CENSOS DE LA TIERRA BLANCA, CONEL VOLUMEN TOTAL DEL AGUA, Y LA RELACION ENTRE LOS DATOS DE UNA Y OTRA GIRADORAS
}

\begin{tabular}{|c|c|c|c|c|c|c|c|}
\hline \multirow[b]{2}{*}{$N^{\circ}$ Ord. } & \multirow{2}{*}{$\begin{array}{c}\text { Partd. } \\
1716\end{array}$} & \multicolumn{3}{|c|}{ Censo } & \multicolumn{3}{|c|}{ Agua } \\
\hline & & 1716 & 1832 & $\underline{716 / 832}$ & 1716 & 1832 & $716 / 832$ \\
\hline 1 & 50 & 4026,4 & 705,1 & 5,7 & 351,5 & 98,5 & 3,5 \\
\hline 2 & 27 & 2021,5 & 529,2 & 3,8 & 46,0 & 9,0 & 5,1 \\
\hline 3 & 7 & 1022,5 & 523,5 & 1,9 & 248,0 & 413,5 & 0,5 \\
\hline 4 & 18 & 954,9 & 580,1 & 1,6 & 181,0 & 138,0 & 1,3 \\
\hline 5 & 2 & 845,1 & 604,2 & 1,3 & 21,0 & 16,0 & 1,3 \\
\hline 6 & 6 & 690,4 & 1319,3 & 0,5 & 102,0 & 291,5 & 0,3 \\
\hline 7 & 22 & 662,7 & 63,2 & 10,4 & 57,0 & 10,5 & 5,4 \\
\hline 8 & 41 & 578,0 & 244,7 & 2,3 & 46,5 & 23,5 & 1,9 \\
\hline 9 & 8 & 471,6 & 956,4 & 0,4 & 77,5 & 125,5 & 0,6 \\
\hline 10 & 12 & 464,0 & 2125,0 & 0,2 & 44,5 & 499,0 & 0,08 \\
\hline 11 & 3 & 340,7 & 137,9 & 2,4 & 58,0 & 22,5 & 2,5 \\
\hline 12 & 5 & 329,3 & 277,0 & 1,1 & 59,5 & 95,5 & 0,6 \\
\hline 13 & 10 & 291,1 & 215,2 & 1,3 & 88,5 & 64,5 & 1,3 \\
\hline 14 & 23 & 195,0 & 100,1 & 1,9 & 20,0 & 10,0 & 2,0 \\
\hline 15 & 15 & 174,2 & -- & -- & 32,0 & -- & -- \\
\hline 16 & 19 & 173,5 & 67,1 & 2,5 & 0,5 & 4,5 & 0,1 \\
\hline 17 & 13 & 135,4 & 84,7 & 1,5 & 24,0 & 64,0 & 0,3 \\
\hline 18 & 17 & 106,8 & -- & -- & 27,0 & - & -- \\
\hline 19 & 20 & 87,1 & -- & -- & 24,0 & -- & -- \\
\hline 20 & 4 & 71,6 & 107,6 & 0,6 & 18,5 & 84,0 & 0,2 \\
\hline 21 & 39 & 71,2 & -- & -- & 6,0 & $-\ldots$ & -- \\
\hline 22 & 16 & 58,8 & 670,7 & 0,08 & 4,0 & 10,5 & 0,3 \\
\hline 23 & 43 & 58,2 & -- & -- & 20,5 & -- & -- \\
\hline 24 & 9 & 56,9 & -- & -- & 21,0 & -- & -- \\
\hline
\end{tabular}

A modo de conclusión, en el Cuadro $X X I$, hemos establecido la relación entre los censos y el agua de las partidas de las dos Giradoras, en el 
que se observa una paralelismo entre las reducciones de censo y agua de la segunda respecto de la primera, algunas muy importantes, como ocurre en las partidas que ocupan los cinco lugares primeros. La partida 7, que aparece en el tercer puesto, reduce los censos pero aumenta considerablemente el volumen del agua recibida. En otras se da un aumento tanto de los censos como del agua, tan importante, en algunos casos, como los de las partidas 8 y 12 . De las dieciocho partida con los datos completos, en sólo cuatro la relación es inversa, crecimiento del agua y reducción de los censos, pero el crecimiento sólo es importante en la partida 7.

\section{b) LA VID}

En el Cuadro XIX vemos, como ya ocurría en la Giradora anterior, que este cultivo se halla concentrado en no muchas partidas, aportando en censos, agua y extensión lo siguiente:

\begin{tabular}{|c|c|c|c|c|}
\hline & Total & $\%$ del total & $\begin{array}{c}\text { Censo/ } \\
\text { Agua \% }\end{array}$ & $\begin{array}{l}\text { Censo/ } \\
\text { Ext. \% }\end{array}$ \\
\hline Censo & 7059,0 & 31,2 & 0,7 & 0,5 \\
\hline Agua & 2294,0 & 44,1 & -- & - \\
\hline Extens. & 2361,3 & 53,5 & & \\
\hline
\end{tabular}

La importancia de estas cifras cobra todo su valor al compararlas con las de la Giradora anterior. El crecimiento de los censos, en términos absolutos, ha sido del $58,3 \%$, y en términos relativos, del $17,2 \%$. En lo concerniente al agua, ha sido, respectivamente, del $82,4 \%$ y del $28,0 \%$. $Y$ la relación censo/agua también ha descendido ligeramente.

En el Cuadro $X X / /$ se han elaborado los datos correspondientes a este tipo de cultivo. Las trece partidas aquí recogidas suponen el $95,3 \%$ de los censos, el $83,9 \%$ del agua y el $95,3 \%$ de la extensión. De ellas, las cinco primeras abarcan el $69,7 \%$, el $38,5 \%$ y el $59,6 \%$ respectivamente.

Respecto a la desproporción que existe con el agua, hemos de tener en cuenta la presencia en el puesto segundo de la partida 2. Las partidas, en términos relativos, están todas bien abastecidas de agua, aunque las de mayor importancia por los censos son las que presentan más altas deficiencias hídricas. En las dos últimas columnas del cuadro se ve la relación inversa o el paralelismo en función del censo, a excepción de las partidas 2, 15 y 71 ("Casa de Sempere»), por su escasez en el abastecimiento de agua. 


\section{CUADRO XXII}

ORDEN DE LAS PARTIDAS CON MAS DE 50 SUELDOS, SEGUN EL \% DEL TOTAL DE LOS CENSOS DE LA VID, CON EL \% DEL AGUA Y DE LA EXTENSION, Y LA RELACION CENSO/AGUA Y CENSO/EXTENSION (GIRADORA DE 1832)

\begin{tabular}{|c|c|c|c|c|c|c|}
\hline$N^{\circ}$ Ord. & $N^{\circ}$ Partd. & $\%$ Censo & \% Agua & $\%$ Extens. & Cens/Agua & Cens/Ext. \\
\hline 1 & 18 & 18,1 & 13,3 & 21,8 & 1,3 & 0,8 \\
\hline 2 & 2 & 17,7 & 1,1 & 6,9 & 16,0 & 2,5 \\
\hline 3 & $1 \overline{5}$ & 16,1 & 3,7 & 14,3 & 4,3 & 1,1 \\
\hline 4 & 3 & 9,0 & 10,8 & 9,4 & 0,8 & 0,9 \\
\hline 5 & 4 & 8,8 & 9,6 & 7,2 & 0,9 & 1,2 \\
\hline 6 & 7 & 6,6 & 16,2 & 11,2 & 0,4 & 0,5 \\
\hline 7 & 5 & 5,3 & 8,6 & 6,8 & 0,6 & 0,7 \\
\hline 8 & 9 & 3,6 & 1,3 & 5,7 & 2,7 & 0,6 \\
\hline 9 & 45 & 3,5 & 6,2 & 3,5 & 0,5 & 1,0 \\
\hline 10 & 20 & 3,0 & 4,2 & 3,4 & 0,7 & 0,8 \\
\hline 11 & 17 & 1,4 & 7,2 & 1,7 & 0,1 & 0.8 \\
\hline 12 & 50 & 1,4 & 1,7 & 1,3 & 0,8 & 1,0 \\
\hline 13 & 71 & 0,8 & -- & 0,2 & -- & 4,0 \\
\hline Totales $\%$ & & 95,3 & 83,9 & 95,3 & & \\
\hline
\end{tabular}

CUADRO XXIII

ORDENACION DE LAS PARTIDAS DE AMBAS GIRADORAS, CON MAS DE 50 SUELDOS, SEGUN EL TOTAL DE LOS CENSOS DE LA VID, CON EL VOLUMEN TOTAL DEL AGUA Y LA RELACION ENTRE LOS DATOS DE UNA Y OTRA GIRADORAS.

\begin{tabular}{|c|c|c|c|c|c|c|c|}
\hline \multirow[b]{2}{*}{$N^{\circ}$ Ord. } & \multirow{2}{*}{$\begin{array}{l}\text { Partd. } \\
1716\end{array}$} & \multicolumn{3}{|c|}{ Censo } & \multicolumn{3}{|c|}{ Agua } \\
\hline & & 1716 & 1832 & $716 / 832$ & 1716 & 1832 & $716 / 832$ \\
\hline 1 & 2 & 773,5 & 1254,9 & 0,6 & -- & 27,0 & -- \\
\hline 2 & 18 & 650,2 & 1281,0 & 0,5 & 122,0 & 400,0 & 0,3 \\
\hline 3 & 3 & 571,0 & 638,3 & 0,8 & 105,0 & 324,5 & 0,3 \\
\hline 4 & 4 & 269,2 & 628,0 & 0,4 & 62,0 & 222,5 & 0,2 \\
\hline 5 & 15 & 165,8 & 1139,6 & 0,1 & 16,0 & 86,5 & 0,1 \\
\hline 6 & 6 & 89,1 & -- & -- & 28,5 & -- & \\
\hline 7 & 5 & 77,8 & 380,2 & 0,2 & 8,5 & 198,0 & 0,04 \\
\hline 8 & 19 & 70,9 & $\ldots$ & $\ldots$ & -- & -- & -- \\
\hline 9 & 17 & 65,3 & 102,7 & 0,6 & 10,5 & 166,0 & 0,06 \\
\hline 10 & 7 & 64,1 & 470,7 & 0,1 & 13,5 & 372,5 & 0,03 \\
\hline
\end{tabular}

Comparando los Cuadro XXIII y XV pueden deducirse los cambios que se han producido en las partidas en relación al total. Las partidas que se repiten en ambos cuadros, suponen en el XXII el $83 \%$ de los censos; pero esta reducción, en términos relativos, se transforma en el Cuadro XXIII, en donde vemos el importante crecimiento que se ha dado en los censos y, más aún, en el agua de la Giradora de 1832 respecto a la de 1716. 


\section{c) EL OLIVO}

Este cultivo aparece disperso por la mitad de las partidas, aunque con no mucha significación, a excepción de tres partidas. Los datos sobre los censos, el agua y la extensión son:

\begin{tabular}{lrcccc} 
& \multicolumn{1}{c}{ Total } & \% del total & $\begin{array}{c}\text { Censo/ } \\
\text { Agua \% }\end{array}$ & $\begin{array}{c}\text { Censo/ } \\
\text { Exts. \% }\end{array}$ \\
\cline { 2 - 3 } Censos & 1190,8 & 5,2 & & 0,9 & 0,6 \\
Agua & 280,0 & 5,3 & & & \\
Extens. & 363,0 & 8,2 & &
\end{tabular}

De nuevo estos datos sólo adquieren significado comparándolos con los de la Giradora anterior. Así, se ha dado una pequeña reducción de los censos, en términos absolutos, y más aún, en términos relativos. En cuanto al agua, se ha dado un pequeño aumento en términos absolutos, pero se ha reducido considerablemente en términos relativos. La relación censo/agua ha aumentado también. A nivel general, por lo tanto, el olivo ha perdido valor.

\section{CUADRO XXIV}

ORDEN DE LAS PARTIDAS CON MAS DE 50 SUELDOS, SEGUN EL \% DEL TOTAL DELOS CENSOS DEL OLIVO, CON EL \% DEL AGUA Y DE LA EXTENSION Y LA RELACION CENSO/AGUA Y CENSO/EXTENSION (GIRADORA DE 1832)

\begin{tabular}{|c|c|c|c|c|c|c|}
\hline$N^{\circ}$ Ord & $N^{0}$ Partd. & $\%$ Censo & \% Agua & $\%$ Extens. & Cens/Agua & Cens/Ext. \\
\hline 1 & 2 & 43,7 & 10,7 & 36,1 & 4,0 & 1,2 \\
\hline 2 & 50 & 8,9 & 0,5 & 2,0 & 17,8 & 4,4 \\
\hline 3 & 5 & 8,4 & 11,5 & 6,6 & 0,7 & 1,2 \\
\hline 4 & 19 & 6,2 & -- & 13,9 & $-\cdots$ & 0,4 \\
\hline 5 & 7 & 4,9 & 31,0 & 5,8 & 0,1 & 0,8 \\
\hline 6 & 13 & 4,5 & 4,8 & 4,1 & 0,9 & 1,0 \\
\hline & ales \% & 76,6 & 58,5 & 68,5 & & \\
\hline
\end{tabular}

Es el Cuadro XXIV el que nos acerca más a los datos. Según este las seis partidas que aportan más de cincuenta sueldos de censo por el olivo suponen el $76,6 \%$ del total, el $58,8 \%$ del agua y el $68,5 \%$ de la extensión. Lo que, a la vez nos exclarece otra cuestión relativa a este cultivo, la existencia de muy pequeñas explotaciones. Entre las partidas consideradas en el cuadro tiene especial importancia la 2, por el censo y la extensión. En cuanto a las dos últimas columnas del cuadro, hay una cierta proporción inversa en las partidas 2 y 50 , por la escasez del agua, y un cierto paralelismo en las partidas 5,7 y 13 . 


\section{CUADRO XXV}

ORDENACION DE LAS PARTIDAS DE AMBAS GIRADORAS, CON MAS DE 50 SUELDOS, SEGUN EL TOTAL DE LOS CENSOS DEL OLIVO; CON EL VOLUMEN TOTAL DEL AGUA, Y LA RELACION ENTRE LOS DATOS DE UNA Y OTRA GIRADORAS

\begin{tabular}{|c|c|c|c|c|c|c|c|}
\hline \multirow[b]{2}{*}{$N^{\circ}$ Ord. } & \multirow{2}{*}{$\begin{array}{l}\text { Part. } \\
1716\end{array}$} & \multicolumn{3}{|c|}{ Censo } & \multicolumn{3}{|c|}{ Agua } \\
\hline & & 1716 & 1832 & $716 / 832$ & 1716 & 1832 & $716 / 832$ \\
\hline 1 & 11 & 945,3 & -- & -- & $\ldots$ & -- & -- \\
\hline 2 & 18 & 250,7 & -- & -- & -- & -- & -- \\
\hline 3 & 50 & 112,1 & 106,3 & 1,0 & 33,0 & 1,5 & 22,0 \\
\hline 4 & 19 & 53,7 & 74,8 & 0,7 & $\ldots$ & -- & -- \\
\hline 5 & 16 & 53,3 & -- & -- & -- & -- & -- \\
\hline
\end{tabular}

En el Cuadro $X X V$ se refleja de manera muy destacada la transformación que se ha dado entre las fechas abarcadas por una y otra Giradoras: sólo dos partidas coinciden en mantener más de cincuenta sueldos de censos, habiendo desaparecido la 11 y la 18 en la Giradora de 1832, y dándose un importante crecimiento en la 2.

La Giradora de 1832 nos informa, además, de otra importante transformación, la práctica desaparición de los que hemos llamado Otras. Los datos correspondientes a estos cultivos son:

\begin{tabular}{cc} 
Total & \% del total \\
\cline { 2 - 2 } 253,0 & 1,1 \\
37,8 & 0,7 \\
96,2 & 2,1
\end{tabular}

En el Cuadro $X I X$, donde se recogen estos datos, vemos que en sólo dos partidas los censos superan los cincuenta sueldos: la 2 y la 18.

Finalmente, en el Cuadro XXVI se nos muestra, de manera comparada, la jerarquía de las partidas en los distintos cultivos a través de los censos en cada uno. A partir de éste puede elaborarse una muestra de las partidas en la que es exclusivo o predomina un determinado cultivo.

Estos últimos datos, comparados con los que aparecen en el Cuadro $X V I I I$, pueden ilustrarnos de la concentración de los cultivos en las partidas, idea que puede convertirse en uno de los primeros puntos de la conclusión. 
CUADRO XXVI

ORDENACION DE LAS PARTIDAS SEGUN LOS CENSOS DE CADA UNO DE LOS CULTIVOS

(GIRADORA DE 1832)

\begin{tabular}{|c|c|c|c|}
\hline$N^{o}$ Orden & Part. / Tierra B. & Part./Vid & Part/Olivo \\
\hline 1 & 12 & 18 & 2 \\
\hline 2 & 6 & 2 & 50 \\
\hline 3 & 84 & 15 & 5 \\
\hline 4 & 8 & 3 & 19 \\
\hline 5 & 7 & 4 & 7 \\
\hline 6 & 85 & 7 & 13 \\
\hline 7 & 50 & 5 & -- \\
\hline 8 & 16 & 9 & -- \\
\hline 9 & 2 & 45 & -- \\
\hline 10 & 18 & 20 & $\ldots$ \\
\hline 11 & 27 & 17 & -- \\
\hline 12 & 42 & 50 & -- \\
\hline 13 & 58 & 71 & -- \\
\hline 14 & 57 & -- & -- \\
\hline 15 & 5 & -- & -- \\
\hline 16 & 11 & & \\
\hline 17 & 41 & & \\
\hline 18 & 45 & & \\
\hline 19 & 10 & & \\
\hline 20 & 3 & & \\
\hline 21 & 88 & & \\
\hline 22 & 4 & & \\
\hline 23 & 23 & . & \\
\hline 24 & 35 & & \\
\hline 25 & 13 & & \\
\hline 26 & 19 & & \\
\hline 27 & 22 & & \\
\hline 28 & 89 & & \\
\hline
\end{tabular}

En segundo lugar, la importancia adquirida por la vid, cuyo crecimiento en censos y agua absorbe la casi totalidad del que se ha dado entre una y otra Giradoras y el originado por la reducción de los "otros» cultivos. 


\begin{tabular}{|c|c|c|c|c|c|}
\hline \multicolumn{2}{|c|}{ Tierra Blanca } & \multicolumn{2}{|c|}{ Vid } & \multicolumn{2}{|c|}{ Olivo } \\
\hline$N^{o}$ Part. & $\%$ Cens. & $N^{\circ}$ Part. & $\%$ Cens. & $N^{o}$ Part. & $\%$ Cens. \\
\hline 12 & 100,0 & 15 & 95,7 & 19 & 47,4 \\
\hline 6 & 98,8 & 3 & 80,5 & 13 & 30,2 \\
\hline 84 & 100,0 & 4 & 84,4 & -- & -- \\
\hline 8 & 95,7 & 9 & 75,5 & & \\
\hline 85 & 100,0 & 20 & 91,1 & & \\
\hline 16 & 99,2 & 17 & 72,3 & & \\
\hline 27 & 100,0 & 71 & 68,9 & & \\
\hline 42 & 100,0 & -- & -- & & \\
\hline 58 & 97,5 & & & & \\
\hline
\end{tabular}

En tercer lugar, el estacionamiento del olivo y de los cultivos en la tierra blanca.

$Y$, finalmente, puede deducirse la transformación del paisaje, por la transformación operada en las partidas.

\section{3. - LA TENENCIA DE LA TIERRA}

Según la Carta de Población las tierras se entregaban a censo perpétuo, que había de pagarse anualmente por la fiesta de San Miguel, y, por tanto, esas tierras podían venderse y transmitirse a los herederos, contando siempre con la autorización del Señor, que conservaba los derechos del Luismo y de la Fadiga (22). A través de los Libros de Giradora se controlaba el movimiento de las tierras, como ya se sabe, y el censo era el elemento más importante que se custodiaba en ellos. En segundo lugar, aportaban los medios para hacer efectivo el derecho del Luismo. De ahí que los otros elementos, excepción hecha del agua, pasarán a ocupar lugares de interés secundario, como la extensión, el tipo de cultivo y la partida rural.

Ante estas circunstancias, para el estudio de la tenencia de la tierra en

(22) En la Carta de Población no aparece ninguna referencia al Luismo ni a la Fadiga; sin embargo, en el pleito de 1673 los vasallos alegaban contra la Señoría sus intentos por aplicar los anteriores derechos.

AME: Processos a la Señoría Directa. Fols. 1-2. En la Concordia, citada en la Nota (5), se establecía que los vasallos habian de pedir licencia para vender sus posesiones, sin pagar nada, pero, a cambio, construirian a sus costas el Pantano. Sin embargo, en los libros de los arrendadores de los derechos dominicales y de los diezmos del Condado de Elda, Petrel y Salinas (sic) existen anotaciones acerca del cobro del luismo. 
el Señorío de Elda, hemos partido del análisis del censo de la tierra, y prescindido de la extensión de las explotaciones y del número de parcelas, ante la problemática existente al no conocer la extensión de un buen número de ellas." Más arriba ya hemos intentado establecer la relación de los censos con la extensión en cada una de las partidas.

En el Cuadro XXVII, recogemos los datos de la Giradora de 17.16. En él puede verse que la relación de los enfiteutas y de los censos pagados es:

\begin{tabular}{|c|c|c|}
\hline$\%$ de Enfiteutas & $\%$ del censo & Censo, por grupos (en libras) \\
\hline 17,0 & 0,7 & $0-0,25$ \\
\hline 24,8 & 1,6 & $0-0,50$ \\
\hline 35,0 & 3,6 & $0-1,00$ \\
\hline 20,1 & 9,3 & $1-2,00$ \\
\hline 18,2 & 16,6 & $2-4,00$ \\
\hline 13,3 & 22,7 & 4- 7,00 \\
\hline 8,5 & 23,7 & $7-11,00$ \\
\hline 20 & 79 & $11-15,00$ \\
\hline 2.6 & 15,6 & $15-23,00$ \\
\hline
\end{tabular}

Así, pues, el $35 \%$ de los enfiteutas paga de censo entre 0 y una libra, que supone el $3,6 \%$ del total, de los que casi la mitad (17\%) pagan sólo de 0 á 0,25 Libra, y poco más de dos tercios pagan entre 0 y 0,50 Libra.

El 20,1\% de los enfiteutas aporta el 9,3\% del censo, y pagan de 1 á 2 libras. La desproporción, por lo tanto, aún siendo muy alta, ha descendido notablemente. De ahí que el $55,1 \%$ de los enfiteutas aporte el $12,9 \%$ del censo, de 0 á 2 libras por enfiteutas.

El $18,2 \%$ de los enfiteutas, que pagan de 2 á 4 libras, aportan el $16,6 \%$ del censo, con lo cual resulta el grupo más equilibrado. A partir de este la relación se desequilibra de nuevo, pero en sentido contrario: El 13,3\% de los enfiteutas, que paga de 4 á 7 libras, aportan el 22,7\% del total del censo, y el desequilibrio sigue en aumento en los grupos siguientes, de manera que la relación que se establece entre los porcentajes de censos y enfiteutas es de:

$23,7 / 8,5=2,7$ para los que pagan entre 7 y 11 libras

$7,9 / 2,0=3,9$ para los que pagan entre 11 y 15 libras

$15,6 / 2,6=6,0$ para los que pagan entre 15 y 23 libras 
CUADRO XXVII

DISTRIBUCION DE LOS ENFITEUTAS POR GRUPOS, SEGUN LOS CENSOS PAGADOS, Y EL \% DEL TOTAL DE LOS ENFITEUTAS Y DE LOS CENSOS

(GIRADORA DE 1716)

\begin{tabular}{|c|c|c|c|c|}
\hline Grupos & T. Enfiteutas & T. Sueldos & $\%$ Enfitas. & $\%$ Censo \\
\hline $0-1$ & 25 & 45,0 & 7,8 & 0,2 \\
\hline $1-5$ & 30 & 99,8 & 9,2 & 0,5 \\
\hline 5- 10 & 25 & 190,4 & 7,8 & 0,9 \\
\hline $10-20$ & 33 & 442,8 & 10,2 & 2,0 \\
\hline $20-30$. & 38 & 987,0 & 11,8 & 4,7 \\
\hline $30-40$ & 27 & 968,7 & 8,3 & 4,6 \\
\hline $40-60$ & 41 & 2232,5 & 12,7 & 10,6 \\
\hline $60-80$ & 18 & 1249,6 & 5,5 & 6,0 \\
\hline $80-100$ & 15 & 1436,0 & 4,6 & 7,0 \\
\hline $100-140$ & 28 & 3297,2 & 8,7 & 15,7 \\
\hline $140-180$ & 18 & 2942,0 & 5,5 & 14,0 \\
\hline $180-220$ & 10 & 2041,4 & 3,0 & 9,7 \\
\hline $220-260$ & 3 & 789,0 & 1,0 & 3,7 \\
\hline $260-300$ & 3 & 885,3 & 1,0 & 4,2 \\
\hline $300-360$ & 6 & 1991,0 & 1,9 & 9,5 \\
\hline $360-420$ & 1 & 410,3 & 0,3 & 1,9 \\
\hline $420-460$ & 2 & 894,7 & 0,6 & 4,2 \\
\hline Total & $\overline{323}$ & $\overline{20902,9}$ & $\overline{99,9}$ & $\overline{99,0}$ \\
\hline
\end{tabular}

Estos tres últimos grupos, que constituyen el $13,8 \%$ de los enfiteutas, 43 en total, aportan el $47,2 \%$ del total del censo, 9953,4 sueldos, que se reparten entre los distintos tipos de cultivo de la siguiente manera:

\begin{tabular}{|c|c|c|c|}
\hline & Total & $\%$ & $\%$ Total \\
\hline Tierra blanca & 6653,7 & 66,8 & 67,9 \\
\hline Vid & 996,9 & 10,0 & $14,0^{\circ}$ \\
\hline Olivo & 885,4 & 8,8 & 7,4 \\
\hline Otras & 1417,4 & 14,2 & 10,5 \\
\hline
\end{tabular}

Los anteriores datos, como puede verse, de la columna segunda, dan unos porcentajes semejantes a los de la columna tercera, que represen- 
tan el \% de los censos, aunque se aprecia una pequeña disminución en la vid, que se compensa con el aumento de "Otras».

En el Cuadro XXVIII se ha establecido la relación de los distintos grupos de enfiteutas y de los censos que pagan, según la Giradora de 1832. A partir de esos datos puede afirmarse:

\begin{tabular}{|c|c|}
\hline$\%$ de Enfiteutas & $\%$ del Censo \\
\hline 24,0 & 0,2 \\
\hline 31,0 & 0,9 \\
\hline 40,9 & 2,6 \\
\hline 14,1 & 5,3 \\
\hline 10,2 & 6,1 \\
\hline 13,0 & 12,3 \\
\hline 6,0 & 8,8 \\
\hline 5,5 & 12,5 \\
\hline 3,8 & 12,0 \\
\hline 3,5 & 18,7 \\
\hline 1,7 & 17,1 \\
\hline 0,3 & 4,6 \\
\hline
\end{tabular}

Censo, por grupos (en libras)
$0-0,25$
$0-0,50$
$0-1,00$
$1-2,00$
2- 3,00
3- 5,00
$5-7,00$
7- 11,00
$11-15,00$
$15-30,00$
$30-50,00$

Más de 50,00

El comentario de estos datos encierra un doble interés: primero, por los datos en sí mismos, $y$, en segundo lugar, por su comparación con los de la anterior Giradora.

Así vemos que aquí es el $40,9 \%$, en lugar del $35,0 \%$, de los enfiteutas, que pagando de 0 á 1 libra, aportan solamente el 2,6\% de los censos, en lugar del $3,6 \%$, de los cuales más de la mitad, el $24 \%$, pagando cantidades mínimas, aportan el $0,2 \%$ del total, $y$ tres cuartas partes de los enfiteutas, el $31 \%$, paga de 0 a 0,5 Libra.

El $14,1 \%$ de los enfiteutas, que pagan de 1 á 2 libras, aportan el $5,3 \%$ del total de los censos, porcentajes sensiblemente menores a los de la anterior Giradora. El 10,2\% de los enfiteutas, de 2 á 3 libras de carga, supone el $6,1 \%$ de los censos. Es decir que la desproporción entre los enfiteutas $y$ los censos pagados se va reduciendo, aunque todavía se mantiene a niveles altos. De este modo, vemos que el $65,2 \%$ de los enfiteutas aportan solamente el $14,0 \%$ del total de los censos, pagando de 0 a tres libras. Lo que significa una mayor desproporción aún que la existente en la anterior Giradora.

El grupo más proporcionado es el de los enfiteutas, que pagando entre 3 y 5 libras, suponen el 13,3\% y aportan el 12,3\% de los censos. 


\section{CUADRO XXVIII}

DISTRIBUCION DE LOS ENFITEUTAS POR GRUPOS, SEGUN LOS CENSOS PAGADOS, Y \% DEL TOTAL DE LOS ENFITEUTAS Y DE LOS CENSOS (GIRADORA DE 1832)

\begin{tabular}{|c|c|c|c|c|c|}
\hline \multicolumn{2}{|c|}{ Grupos } & \multirow{2}{*}{$\frac{\text { T. Enfiteutas }}{48}$} & \multirow{2}{*}{$\frac{\text { T. Sueldos }}{0,8}$} & \multirow{2}{*}{$\frac{\% \text { Enfitas. }}{17,0}$} & \multirow{2}{*}{$\frac{\% \text { Censo }}{0,0}$} \\
\hline 0 - & 1 & & & & \\
\hline $1-$ & 5 & 20 & 61,8 & 7,0 & 0,2 \\
\hline $5-$ & 10 & 20 & 144,9 & 7,0 & 0,7 \\
\hline $10-$ & 20 & 28 & 367,8 & 9,9 & 1,7 \\
\hline $20-$ & 30 & 18 & 460,5 & 6,3 & 2,0 \\
\hline $30-$ & 40 & 22 & 747,0 & 7,8 & 3,3 \\
\hline $40-$ & 60 & 29 & 1398,8 & 10,2 & 6,1 \\
\hline 60 & 80 & 19 & 1210,0 & 6,7 & 5,3 \\
\hline $80-$ & 100 & 18 & 1569,7 & 6,3 & 7,0 \\
\hline 100 & 140 & 17 & 1986,4 & 6,0 . & 8,8 \\
\hline $140-$ & 180 & 9 & 1415,5 & 3,1 & 6,2 \\
\hline $180-$ & 220 & 7 & 1433,1 & 2,4 & 6,3 \\
\hline 220 & 260 & 6 & 1349,4 & 2,1 & 6,0 \\
\hline $260-$ & 300 & 5 & 1343,0 & 1,7 & 6,0 \\
\hline $300-$ & 350 & 2 & 666,0 & 0,7 & 3,0 \\
\hline $350-$ & 400 & 2 & 763,2 & 0,7 & 3,3 \\
\hline 400 & 450 & 2 & 849,4 & 0,7 & 3,8 \\
\hline $450-$ & 500 & 2 & 934,3 & 0,7 & 4,1 \\
\hline $500-$ & 600 & 2 & 1034,1 & 0,7 & 4,5 \\
\hline $600-$ & 700 & 1 & 602,8 & 0,3 & 2,6 \\
\hline 700 & 800 & 2 & 1459,4 & 0,7 & 6,4 \\
\hline $800-$ & 1000 & 2 & 1826,7 & 0,7 & 8,1 \\
\hline Más & 1000 & 1 & 1051,2 & 0,3 & 4,6 \\
\hline & Total & 282 & 22568,3 & 99,0 & 100,0 \\
\hline
\end{tabular}

Sin embargo, aquí encontramos también una reducción, tanto en términos absolutos como relativos, del número de los enfiteutas y del porcentaje de los censos, y, en cambio, ha subido la cuota a pagar, ya que en la anterior era de 2 á 4 libras.

En los grupos siguientes aparece de nuevo la desproporción, que irá aumentando progresivamente: Los que pagan de 5 á 7 libras suponen el $6 \%$ de los enfiteutas y aportan el $8,8 \%$ de los censos. Y la relación que 
existe entre los porcentajes de los censos y de los enfiteutas de los grupos siguientes es de:
$12,5 / 5,5=2,2$ para los que pagan de 7 á 11 libras
$12,0 / 3,8=3,1$ para los que pagan de 11 á 15 libras
$18,7 / 3,5=5,3$ para los que pagan de 15 á 30 libras
$17,1 / 1,7=10,0$ para los que pagan de 30 á 50 libras
$4,6 / 0,3=15,3$ para los que pagan más de 50 libras

Estos cinco grupoș suponen el $14,8 \%$ de los enfiteutas, y aportan el $64,9 \%$ del censo. En términos absolutos, son 43 enfiteutas que pagan 14727,9 sueldos de censo. En donde, de nuevo, aparecen importantes elementos, sobre todo si se comparan con los extraídos de la anterior Giradora. En la de 1832 existen grupos de enfiteutas que pagan mayor cantidad de censos que en la de 1716, la desproporción entre los porcentajes de los censos y de estos grupos de enfiteutas es también mayor, $y$, finalmente, el peso de estos grupos minoritarios supera grandemente el de sus antecesores, por la cuantía de los censos.

Es fácil intuir, por lo tanto, que se ha dado una concentración de la tierra, que ha afectado, como hemos visto, a los otros grupos de enfiteutas: ha aumentado el número de los más pequeños, disminuido el número de los medios, $y$, en cambio, aumentado la cuota a pagar por éstos.

Los censos de los grupos más pudientes se reparten del siguiente modo entre los distintos tipos de cultivo:

\begin{tabular}{lrrrr} 
& \multicolumn{1}{c}{ Total } & & $\%$ & $\%$ Total \\
\cline { 2 - 2 } Tierra Blanca & 9877,9 & & 67,0 & 62,3 \\
Vid & 3936,8 & 26,7 & 31,2 \\
Olivo & 785,9 & 5,3 & 5,2 \\
Otras & 127,3 & 0,8 & 1,1
\end{tabular}

Como se ve el reparto es semejante al que resulta de la anterior Giradora, comparando los datos de la columna segunda con los de la tercera, los generales, incluida la disminución de la vid y la compensación de la tierra blanca. Del mismo modo, el aumento de la vid, según la Giradora de 1832, compensa la reducción del olivo y, sobre todo, la del cultivo de "otras», aparte las nuevas superficies dedicadas principalmente al viñedo y que contribuyen a alterar la distribución de los porcentajes. 